NBER WORKING PAPER SERIES

\title{
STICKY PRICES VERSUS MONETARY FRICTIONS: AN ESTIMATION OF POLICY TRADE-OFFS
}

\author{
S. Boragan Aruoba \\ Frank Schorfheide \\ Working Paper 14870 \\ http://www.nber.org/papers/w14870
NATIONAL BUREAU OF ECONOMIC RESEARCH
1050 Massachusetts Avenue
Cambridge, MA 02138
April 2009

Previous versions of this paper circulated as "Insights from an Estimated Search-Based Monetary Model with Nominal Rigidities". We thank Randy Wright for valuable discussions and Sanjay Chugh, Kai Christoffel, Peter Ireland, Chris Otrok, Giorgio Primiceri, Alex Wolman, as well as seminar participants at various institutions and conferences for helpful comments. Maxym Kryshko provided excellent research assistance. Schorfheide gratefully acknowledges financial support from the Alfred P. Sloan Foundation and the National Science Foundation under Grant SES 0617803. The views expressed herein are those of the author(s) and do not necessarily reflect the views of the National Bureau of Economic Research.

NBER working papers are circulated for discussion and comment purposes. They have not been peerreviewed or been subject to the review by the NBER Board of Directors that accompanies official NBER publications.

(C) 2009 by S. Boragan Aruoba and Frank Schorfheide. All rights reserved. Short sections of text, not to exceed two paragraphs, may be quoted without explicit permission provided that full credit, including (c) notice, is given to the source. 
Sticky Prices Versus Monetary Frictions: An Estimation of Policy Trade-offs

S. Boragan Aruoba and Frank Schorfheide

NBER Working Paper No. 14870

April 2009

JEL No. C5,E4,E5

\begin{abstract}
We develop a two-sector monetary model with a centralized and decentralized market. Activities in the centralized market resemble those in a standard New Keynesian economy with price rigidities. In the decentralized market agents engage in bilateral exchanges for which money is essential. The model is estimated and evaluated based on postwar U.S. data. We document its money demand properties and determine the optimal long-run inflation rate that trades off the New Keynesian distortion against the distortion caused by taxing money and hence transactions in the decentralized market. Target rates of $-1 \%$ or less maximize the social welfare function we consider, which contrasts with results derived from a cashless New Keynesian model.
\end{abstract}

\author{
S. Boragan Aruoba \\ Department of Economics \\ University of Maryland \\ 3105 Tydings Hall \\ College Park, MD 20742-7211 \\ aruoba@econ.umd.edu \\ Frank Schorfheide \\ University of Pennsylvania \\ Department of Economics \\ 3718 Locust Walk \\ McNeil 525 \\ Philadelphia, PA 19104-6297 \\ and NBER \\ schorf@ssc.upenn.edu
}




\section{Introduction}

The standard framework used for monetary policy analysis for the last decade in academic research, especially at central banks, the so-called New Keynesian model, is one where various nominal rigidities are central. The framework prescribes near-zero inflation as a long-run goal. This policy prescription arises from the most stripped-down version of the framework, where capital is absent and the only friction is that firms face a cost for adjusting nominal prices, and it holds true in much more complicated environments. A large fraction of models within this framework adopt a cashless perspective under which the motive that generates money demand is not made explicit. The prevalent view is that the explicit modeling of money demand does not alter the welfare prescriptions of New Keynesian models. Only a handful of previous studies carefully consider frictions that generate money demand alongside nominal rigidities when studying optimal monetary policy. We are contributing to this literature by developing a new model in which demand for money arises because currency facilitates bilateral exchange in decentralized markets and nominal rigidities are present in the centralized markets. We estimate different versions of our model based on aggregate U.S. data and evaluate its fit through comparisons with two reference models. Our estimates imply that negative target inflation rates in the range of $-2 \%$ to $-1 \%$ lead to a lower welfare cost relative to a zero inflation target.

Our contributions are threefold. First, we develop a dynamic stochastic general equilibrium (DSGE) model that bridges the gap between the search-based monetary theory initiated by Kiyotaki and Wright (1989) and the literature on estimable New Keynesian DSGE models laid out in the textbook by Woodford (2003). Contrary to popular belief, it is fairly straightforward to combine interesting elements of the monetary micro foundations literature with New Keynesian models and create empirical models that can be confronted with the data and used to study important substantive questions. In our model, following the basic structure of Lagos and Wright (2005, henceforth LW) and Aruoba, Waller, and Wright (2008, henceforth AWW), in every period economic activity takes place in two markets. In a decentralized market (DM), households engage in bilateral trade, with a fraction of households producing and a fraction of households consuming. The terms of trade in the bilateral exchange are either determined by bargaining (B) or Walrasian price taking (PT). The centralized market (CM) resembles a standard DSGE model with admittedly reducedform nominal rigidities, where production is carried out by firms. Physical capital is a factor of production in both markets. Demand for money arises because the particular frictions in the decentralized markets necessitate the facilitation of transactions by a medium of exchange. We represent monetary policy by an interest rate feedback rule, and introduce stochastic disturbances to technology, preferences, government spending, and monetary policy to make the model amenable to econometric estimation methods. While the structure of our model to a large extent resembles that of a canonical New Keynesian model with capital, the presence of the decentralized market provides a micro-founded motive for holding money and creates a nonseparability between consumption and the value of real money balances. Most important for the subsequent 
policy analysis, our model incorporates two key channels through which inflation can affect welfare. First, non-zero inflation rates lead to relative price distortions and inefficient use of intermediate goods because it is costly for firms to adjust nominal prices. We label this channel the New Keynesian channel. Second, non-zero nominal interest rates constitute a tax on money holdings and hence depress activity in the decentralized market. We label this channel the Friedman channel.

The second contribution is the estimation and evaluation of our proposed model, using post-war U.S. data on output, inflation, interest rates, and inverse M1 velocity. While most of the work on search-based monetary models has been theoretical, we use the Bayesian techniques surveyed in An and Schorfheide (2007) to conduct a full-fledged econometric analysis. In particular, we obtain posterior distributions for the parameters that control the strength of the New Keynesian and the Friedman channels. A novel feature of our estimation is that we construct a measure of the target inflation rate from low frequency dynamics of inflation as well as inflation expectations and then use this series along with output, inflation, interest rates, and velocity to estimate the DSGE model. To assess the fit of the search-based DSGE model we also estimate a vector autoregression (VAR) and a standard New Keynesian model in which real money balances enter the households' utility function (MIU) in a separable fashion and conduct a detailed comparison. Under the assumption that agents forecast the target inflation rate with a random walk model, we are able to identify impulse responses to a target inflation rate shock in the DSGE models as well as the VAR. Responses to this shock are informative for the subsequent policy analysis in which we will examine the effect of target inflation changes on welfare. An impulse response function comparison shows that the Bayesian estimates of different versions of the DSGE models only capture the small short-run elasticity of velocity with respect to interest rates, but not the larger long-run elasticity. In turn, we generate a second set of loss-function based estimates, which reproduce the long-run (but not the short-run) interest rate elasticity of money demand.

The third contribution of the paper is the policy analysis where we examine steady state welfare effects of changes in the target inflation rate. In particular, we compute measures of welfare gain of changing the target inflation from our end-of-sample value of $2.5 \%$ to a new value $\bar{\pi}_{*}$. Since both the New Keynesian and the Friedman channels "agree" that positive target inflation rates are undesirable, we focus on the range of $\bar{\pi}_{*} \in[-2.5 \%, 0 \%]$, where $2.5 \%$ corresponds to the real rate in our model. At $\bar{\pi}_{*}=-2.5 \%$ the nominal interest rate is zero, which is the celebrated "Friedman rule."

The strength of the New Keynesian channel is determined by the probability with which firms are able to re-optimize their prices - we use a Calvo (1983) style nominal rigidity in the centralized market - and the degree to which non-optimizing firms index their past price to lagged inflation. The Friedman channel is to a large extent controlled by the probability with which households engage in bilateral exchange in the decentralized market, which in turn determines the semi-interest elasticity of money demand. Moreover, as emphasized in AWW, determining the terms of trade in the DM by bargaining creates two hold-up problems 
that amplify the welfare costs of inflation. With posterior draws of the DSGE model parameters in hand, we ask the following question. Given $\bar{\pi}_{*}$, what is the probability that the regret - defined as the difference of welfare gain between the target inflation rate that is optimal for a particular parameter draw and $\bar{\pi}_{*}-$ is small. We find that a small regret is attained for most versions of our search-based model for target inflation rates of $-1 \%$ or less, which contrasts with the result derived from a cashless New Keynesian model.

Our paper is related to several strands of the literature in monetary economics and the estimation of DSGE models. While the literature on estimated DSGE models with New Keynesian features is large - see Schorfheide (2009) for an extensive survey - only very few papers use a measure of money as observable and hence implicitly or explicitly estimate a DSGE model-implied money demand function: Christiano, Eichenbaum and Evans (2005), Andres, Lopez-Salido, and Nelson (2004, 2007), Ireland (2004), Bouakez, Cardia, and Ruge-Murcia (2005, 2009), Christensen and Dib (2008), Guerron-Quintana (2008, 2009). Most of these authors introduce money through an MIU specification that captures the value of transaction services derived from money holdings in a reduced-form manner. Guerron-Quintana (2008, 2009) emphasizes the distinction between short- and long-run interest rate elasticities of money demand and introduces short-run costs of adjusting money balances into his MIU model. He reports estimates of a short-run elasticity of about one and a long-run elasticity of approximately 13. In our search-based model (as in a standard MIU model), short- and long-run elasticities are tightly linked and there is no free parameter to disentangle the two. Hence, we offer two types of estimates: a likelihood-based estimate that captures short-run dynamics in the data and a loss-function based estimate that is designed to match the long-run elasticity.

The search-theoretic literature for the most part has only recently started conducting quantitative exercises. Our paper is the first in applying formal estimation methods to a model based the Lagos and Wright (2005) model. Most of the policy analysis in the search-theoretic literature focuses on the optimal long-run monetary policy. In general, for example as in LW and AWW, the Friedman rule is found to be the optimal policy unless the model features some other frictions: some examples are endogenous participation (Rocheteau and Wright, 2005), credit rationing by banks (Berentsen, Camera and Waller, 2007) or government-financing (Aruoba and Chugh, 2007, 2008). The New Keynesian channel and its potential influence on monetary policy has not been analyzed in this class of models before.

There is a large literature on monetary policy analysis in New Keynesian models. Much of the New Keynesian literature, as summarized in Woodford (2003), focuses on stabilization policies, assuming the absence of steady state distortions. For example, Levin, Onatski, Williams, and Williams (2006) analyze policy implications of an estimated medium-scale DSGE model under parameter uncertainty. There are also some papers that focus on the long-run policy, but for the most part, they abstract from monetary frictions. For example, Goodfriend and King (1997) is one of the first papers to argue that in the absence of monetary frictions, the optimal long-run policy is price stability. Examples of the very few papers that consider both 
of these frictions simultaneously are Guerron-Quintana (2008), King and Wolman (1996), Khan, King, and Wolman (2003) and Schmitt-Grohe and Uribe (2007). Guerron-Quintana (2008) with his estimated MIU model focuses on the steady state welfare effects of reducing inflation from $12 \%$ to $2 \%$, accounting for the transition from high to low inflation. The remaining papers analyze the trade-off between the New Keynesian and the Friedman channel and this is also our focus in this paper. King and Wolman (1996) show that once monetary frictions that generate money demand, shopping-time in their case, are added to the most strippeddown New Keynesian model, the Friedman rule is approximately optimal. Khan, King, and Wolman (2003) use a different framework from Calvo-type price stickiness - one where the probability of a price change for a firm depends on the time since last change - and the optimal long-run inflation target in their benchmark calibration is $-0.75 \%$. Schmitt-Grohe and Uribe (2007) show that in a medium-scale New Keynesian model, one with more frictions than ours, and with a transaction cost of consumption to motivate money demand, the optimal policy is a long-run inflation target of $-0.5 \%$, but it is very sensitive to changing the degree of price stickiness.

The size of the New Keynesian distortion in a Calvo framework depends crucially on assumptions about the prices set by firms that are unable to re-optimize. In our model a fraction $\iota$ of these firms update their prices by lagged inflation, whereas a fraction $1-\iota$ update them according to some static multiplier $\pi_{* *}$. In many estimated DSGE models, e.g., Smets and Wouters (2003, 2007), Rabanal and Rubio-Ramirez (2005), Levin, Onatski, Williams, and Williams (2006), Justiniano and Primiceri (2008), it is assumed that $\pi_{* *}$ equals the steady state inflation rate, which essentially eliminates the New Keynesian distortion from long-run considerations. ${ }^{1}$ In our analysis we will set $\pi_{* *}=1$, which preserves the steady state effects of the New Keynesian distortion provided that $\iota<1$. The benchmark calibration in Schmitt-Grohe and Uribe (2007) features no dynamic indexation, that is, $\iota=0$, and uses $\zeta=0.8$. The calibration in Khan, King and Wolman (2003) resembles, but is not equivalent to, a parametrization of our model with $\zeta=0.8$ and $\iota=0$. As such, it seems that these two papers are similarly calibrated and they both find a small level of deflation to be optimal.

By and large, the target inflation prescriptions obtained from our search-based DSGE model, while obtained under very different assumptions about the demand for money, are consistent with this earlier work which gets a range of results between the Friedman rule and full price stability. We differ from the literature above in two aspects. First, we discipline our analysis by making fairly standard choices about utility and production functions defined over consumption goods, instead of choosing arguably arbitrary functional forms for the utility derived from real money balances or the cost of transactions. Second, we identify the parameters that determine the strength of various channels that have conflicting long-run policy implications within our model, in an internally consistent way, as opposed to, for example, independently

\footnotetext{
${ }^{1}$ The sensitivity of policy analysis to assumptions about $\pi_{* *}$ has recently been emphasized by Ascari and Ropele (2007).
} 
calibrating these parameters. Moreover, we are easily able to account for parameter uncertainty in the policy analysis using our Bayesian framework.

There are two important caveats to our policy analysis. First, we abstract from aggregate uncertainty in the policy analysis and the effects of a potentially binding zero lower bound on policy analysis. The analysis in Billi (2008) in the context of a cash-less New Keynesian model without capital suggests that accounting for the zero-lower bound in a stochastic environment might lead to a slightly larger optimal target inflation rate than found in this paper. Second, we focus on the policy trade-offs between two particular channels and do not include some of the other channels in our analysis such as downward rigidity of nominal wages that has been previously considered in the literature. Our results should be interpreted to say that when one only considers these two channels the policy that minimizes the social welfare function we consider is to have a long-run inflation target of less than $-1 \%$.

The remainder of the paper is organized as follows. We provide a detailed derivation and discussion of the search-based DSGE model in Section 2. The Bayesian estimation results are presented in Section 3 and the welfare analysis is summarized in Section 4. Finally, Section 5 concludes. Detailed derivations as well as additional estimation results are provided in an appendix that is available electronically.

\section{The Model}

The model is an extension of the two-sector model developed in LW. In every period, there is economic activity in two markets, which we label as the decentralized (DM) and the centralized market (CM). In the DM, households engage in decentralized bilateral trade in which one party produces and the other consumes. The CM resembles a standard macro model where production is carried out by firms and transactions take place in centralized labor and goods markets. We extend the LW model along two dimensions. First, we include physical capital as a factor of production in the centralized as well as the decentralized market, following AWW. The only deviation we have from AWW in this regard is that we introduce an adjustment cost for investment to improve the empirical fit. Second, to generate price stickiness we replace the perfectly competitive CM firms by monopolistically competitive firms that are constrained in their ability to change nominal prices. The centralized market is essentially identical to the goods market in a standard New Keynesian DSGE model (see Woodford, 2003) with a Calvo (1983) friction.

In turn we will describe the households' decision problems in both the centralized and the decentralized market (Section 2.1) and the firms' problem in the centralized market (Section 2.2). We then characterize the behavior of fiscal policy (Section 2.3), derive an aggregate resource constraint (Section 2.4) and characterize monetary policy (Section 2.5). Our model economy is subject to aggregate disturbances as we show in 
Section 2.6. A summary of all of the equilibrium conditions and more details for some of the derivations are provided in the Appendix.

\section{$2.1 \quad$ Households}

There is a continuum of ex-ante identical households in the economy. In every period, households first trade in the DM. According to an idiosyncratic taste shock that is realized at the beginning of the period, households become buyers with probability $\sigma$, sellers with probability $\sigma$, or non-participants with probability $1-2 \sigma$. These shocks are independent across time and across households. When a household receives the shock that makes it a buyer, it wants to consume in the DM and cannot produce. Similarly, a seller does not wish to consume, but is able to produce for another household. The taste shocks create a double-coincidence problem where frictionless barter cannot occur. ${ }^{2}$ All households are anonymous in this market which means their possible trading partners cannot identify them and therefore will not accept any IOUs. Kiyotaki and Wright (1989) showed that a double-coincidence problem, of the type created by the taste shocks and the anonymity of households, will make money "essential" in the decentralized market, since trade can only happen with a quid pro quo. In a monetary equilibrium, the buyer uses money to purchase the good from the seller. ${ }^{3}$ Thus, the desire to consume in the DM generates a demand for money in our model. Given that there are equal measures of buyers and sellers, we assume there is an efficient matching technology that matches exactly one buyer with one seller. The terms of trade in such a match are determined via one of two alternative schemes: generalized Nash bargaining or price-taking.

Once the households leave the DM, they proceed to the CM where neither of the two frictions that create a role for money in the DM is present: the households are identical in their preferences and abilities and they are not anonymous. This means that there is no role for a medium of exchange in the CM. Using labor and capital income, the households acquire the final goods produced in the CM and use them for consumption and to accumulate capital. Households also adjust their asset holdings. We assume that households have access to a set of claims contingent on all possible realizations of the aggregate states. To characterize the household's behavior in this economy, we start from the problem of the household in the CM, followed by the DM problem.

\subsubsection{Household Activity in the Centralized Market}

The households take as given the aggregate price level in the CM, $P_{t}$, the gross nominal interest rate $R_{t}$ on one-period bonds, the wage $W_{t}$, the rental rate of capital, $R_{t}^{k}$, and the set of aggregate shocks $\mathcal{S}_{t}$, along with

\footnotetext{
${ }^{2} \mathrm{AWW}$ show that a search-based setup in which households meet at random leads to the same mathematical construct.

${ }^{3}$ As with any deep model of money, there is a non-monetary equilibrium in this model that is dominated by the monetary equilibrium in terms of welfare. We focus on the monetary equilibrium.
} 
their laws of motion. We use $V_{t}^{C M}\left(\hat{m}_{t}, k_{t}, i_{t-1}, b_{t}, \mathcal{S}_{t}\right)$ and $V_{t}^{D M}\left(m_{t}, k_{t}, i_{t-1}, b_{t}, \mathcal{S}_{t}\right)$ to denote the period $t$ value functions in the CM and DM, where $\hat{m}_{t}$ is the money balance of a household entering the CM, $k_{t}$ is its capital stock, $i_{t-1}$ is lagged investment, and $b_{t}$ denotes its bond holdings. The CM problem takes the form ${ }^{4}$

$$
\begin{aligned}
V_{t}^{C M}\left(\hat{m}_{t}, k_{t}, i_{t-1}, b_{t}, \mathcal{S}_{t}\right) & =\max _{x_{t}, h_{t}, m_{t+1}, i_{t}, k_{t+1}, b_{t+1}}\left\{U\left(x_{t}\right)-A h_{t}+\beta E_{t}\left[V_{t+1}^{D M}\left(m_{t+1}, k_{t+1}, i_{t}, b_{t+1}, \mathcal{S}_{t+1}\right)\right]\right\} \\
\text { s.t. } & \\
P_{t} x_{t}+P_{t} i_{t}+b_{t+1}+m_{t+1} & \leq P_{t} W_{t} h_{t}+P_{t} R_{t}^{k} k_{t}+\Pi_{t}+R_{t-1} b_{t}+\hat{m}_{t}-T_{t}+\Omega_{t} \\
k_{t+1} & =(1-\delta) k_{t}+\left[1-S\left(\frac{i_{t}}{i_{t-1}}\right)\right] i_{t}
\end{aligned}
$$

Here $U\left(x_{t}\right)$ is the instantaneous utility from consuming $x_{t}$ units of the final good, $A$ is the disutility of one unit of labor, $h_{t}$ is hours worked, $T_{t}$ is a nominal lump-sum tax, $\Pi_{t}$ denotes the total profits the household receives from intermediate good producers, and $\Omega_{t}$ is the household's net cash-in-flow from trading state-contingent securities. The assumption of quasi-linear preferences is crucial and leads to a degenerate distribution of asset holdings at the end of each period. ${ }^{5}$

Equation (2) determines the capital accumulation. The adjustment cost function $S($.$) satisfies properties$ $S(1)=0, S^{\prime}(1)=0$ and $S^{\prime \prime}(1)>0$. We adopt the timing convention that $k_{t+1}$ and $m_{t+1}$ denote capital and money holdings at the end of period $t$ and do not depend on period $t+1$ shocks. Derivations in the appendix show that since the individual state variables $\left(\hat{m}_{t}, k_{t}, i_{t-1}, b_{t}\right)$ do not appear in the household's optimality conditions, the household's decisions in the CM do not depend on its state variables. More specifically, for any distribution of assets $\left(\hat{m}_{t}, k_{t}, b_{t}\right)$ across agents entering the CM, the distribution of $\left(m_{t+1}, k_{t+1}, b_{t+1}\right)$ is degenerate. ${ }^{6}$ Second, we show that $V_{t}^{C M}($.$) is linear in \hat{m}_{t}$ which will be important in the DM problem below. Finally, the Lagrange multiplier associated with the households' nominal budget constraint (1) is $U^{\prime}\left(x_{t}\right) / P_{t}$. Under the assumption that households have access to a set of claims contingent on all possible realizations of the aggregate states, along with quasi-linearity of preferences in the CM, we obtain

$$
\Xi_{t+s \mid t}^{p}=\frac{U^{\prime}\left(x_{t+s}\right) / P_{t+s}}{U^{\prime}\left(x_{t}\right) / P_{t}}
$$

which the firms use to discount future profits.

\footnotetext{
${ }^{4}$ We could index households with $j$, but we will see that the index will drop out of most of these variables due to quasi-linearity of preferences since in equilibrium households will make the same choice of consumption, money demand, and investment. So, we drop this index from the outset.

${ }^{5}$ This assumption can be motivated, as is done in the RBC model of Hansen (1985), by the indivisible labor setup of Rogerson (1988). See Rocheteau et al. (2008a) and Rocheteau et al. (2008b) for details.

${ }^{6}$ This result requires a small qualification for bond holdings. See the appendix.
} 


\subsubsection{Household Activity in the Decentralized Market}

The value of starting the DM for a household whose taste shock has not been realized yet is given by

$$
\begin{aligned}
V_{t}^{D M}\left(m_{t}, k_{t}, i_{t-1}, b_{t}, \mathcal{S}_{t}\right)= & \sigma V_{t}^{b}\left(m_{t}, k_{t}, i_{t-1}, b_{t}, \mathcal{S}_{t}\right)+\sigma V_{t}^{s}\left(m_{t}, k_{t}, i_{t-1}, b_{t}, \mathcal{S}_{t}\right) \\
& +(1-2 \sigma) V_{t}^{C M}\left(m_{t}, k_{t}, i_{t-1}, b_{t}, \mathcal{S}_{t}\right)
\end{aligned}
$$

where the values of being a buyer and a seller are

$$
\begin{aligned}
V_{t}^{b}\left(m_{t}, k_{t}, i_{t-1}, b_{t}, \mathcal{S}_{t}\right) & =\chi_{t} u\left(q_{t}^{b}\right)+V_{t}^{C M}\left(m_{t}-d_{t}^{b}, k_{t}, i_{t-1}, b_{t}, \mathcal{S}_{t}\right) \\
V_{t}^{s}\left(m_{t}, k_{t}, i_{t-1}, b_{t}, \mathcal{S}_{t}\right) & =-c\left(q_{t}^{s}, k_{t}, Z_{t}\right)+V_{t}^{C M}\left(m_{t}+d_{t}^{s}, k_{t}, i_{t-1}, b_{t}, \mathcal{S}_{t}\right) .
\end{aligned}
$$

A household that consumes $q_{t}$ units of the consumption good in the DM receives utility $\chi_{t} u\left(q_{t}\right)$. The disturbance $\chi_{t}$ is a preference shock for goods produced in the DM. Since money is essential to purchase DM goods, $\chi_{t}$ can also be interpreted as a money demand shock. A seller household in the DM experiences disutility $-e_{t}$, where $e_{t}$ denotes the effort the household exerts to produce $q_{t}$ units of the DM good according to the technology $q_{t}=Z_{t} f\left(e_{t}, k_{t}\right)$. The total factor productivity process $Z_{t}$ is assumed to be exogenous and common across DM and CM. We invert the production function to express the level of effort as $e_{t}=$ $c\left(q_{t}, k_{t}, Z_{t}\right)$, which appears in (6). Finally, $q_{t}^{b}\left(q_{t}^{s}\right)$ and $d_{t}^{b}\left(d_{t}^{s}\right)$ denote output and money exchanged when buying (selling). The terms of trade are determined via bilateral generalized Nash bargaining, which is one of the most common schemes in the search literature, or price taking, which was first considered by Rocheteau and Wright (2005). Apart from the mechanics, an important difference between these two schemes is the absence of holdup problems in the price-taking version.

Bargaining. Exploiting the linearity of the $\mathrm{CM}$ value function, and using threat points that have the agents continuing to the $\mathrm{CM}$, our bargaining problem is

$$
\max _{q, d}\left[\chi u(q)-\frac{A d}{P W}\right]^{\theta}\left[\frac{A d}{P W}-c\left(q, k^{s}, Z\right)\right]^{1-\theta} \text { s.t. } d \leq m^{b},
$$

where $\theta$ is the bargaining power of the buyer. The first term captures the buyer's surplus and the second term is the seller's surplus. We dropped the time subscripts since the bargaining problem is static. Using the insights of LW and AWW, in any monetary equilibrium $d=m^{b}$, that is the buyer spends all his money in exchange for some $q$ that the seller produces using his capital and effort. Inserting $d=m^{b}$ and taking the FOC with respect to $q$, one can show that

$$
\frac{m^{b}}{P}=\frac{g\left(q, k^{s}, \chi, Z\right) W}{A} .
$$

where $g($.$) is a function of various primitive functions. The quantity q$ of goods produced can be obtained by solving (7) for $q$ as a function of $m^{b}, k^{s}, \chi$, and $Z$. In the equilibrium conditions in Section 2.1.3, we use $\gamma($.$) defined as$

$$
\gamma(q, k, \chi, Z) \equiv c_{k}(q, k, Z)+c_{q}(q, k, Z) \frac{\partial q\left(m^{\prime} k, \chi, Z\right)}{\partial k}<0
$$


where $c_{q}\left(c_{k}\right)$ denotes the partial derivative of the cost function $c\left(q_{t}, k_{t}, Z_{t}\right)$ with respect to its first (second) argument, and $-\gamma($.$) captures a seller's marginal return of capital in the DM. In particular, having more$ capital will reduce the seller's cost for a given quantity produced, which is captured by the $c_{k}$ term. However, due to the non-competitive nature of the DM under this pricing scheme, having more capital for the seller will also affect the terms of trade by increasing the output produced and this will increase his cost. This second term is the source of one of the holdup problems.

Price-Taking. With price taking, the DM value function has the same form as (4), but now

$$
\begin{aligned}
V_{t}^{b}\left(m_{t}, k_{t}, i_{t-1}, b_{t}, \mathcal{S}_{t}\right) & =\max _{q}\left\{\chi_{t} u(q)+V_{t}^{C M}\left(m_{t}-\tilde{p} q, k_{t}, i_{t-1}, b_{t}, \mathcal{S}_{t}\right)\right\} \text { s.t. } \tilde{p} q \leq m \\
V_{t}^{s}\left(m_{t}, k_{t}, i_{t-1}, b_{t}, \mathcal{S}_{t}\right) & =\max _{q}\left\{-c\left(q_{t}^{s}, k_{t}, Z_{t}\right)+V_{t}^{C M}\left(m_{t}+\tilde{p} q, k_{t}, i_{t-1}, b_{t}, \mathcal{S}_{t}\right)\right\}
\end{aligned}
$$

where $\tilde{p}$ is the DM price level taken as given by the household and the constraint in the buyer's problem ensures the quid pro quo nature of trade in the DM. Market clearing guarantees that buyers and sellers choose the same $q$ and buyers will choose to spend all of their money so that $q=m^{b} / \tilde{p}$ will hold. From the resulting FOC one can derive the analog to (7) in the bargaining model:

$$
\frac{m^{b}}{P}=\frac{q c_{q}\left(q, k^{s}, Z\right) w}{A}
$$

which can be solved for the quantity produced $q$ as a function of $m^{b}, k^{s}$, and $Z$.

\subsubsection{Households' Optimality Conditions}

We define $\mu_{t} \equiv \Upsilon_{t} / U^{\prime}\left(x_{t}\right)$ as the shadow price of capital where $\Upsilon_{t}$ is the multiplier in front of (2). Formally, taking as given $\left\{P_{t}, R_{t}, W_{t}, R_{t}^{k}, \Pi_{t}, T_{t}\right\}_{t=0}^{\infty}$ and exogenous aggregate states $\left\{Z_{t}, \chi_{t}\right\}_{t=0}^{\infty}$, the household solves for $\left\{q_{t}, x_{t}, m_{t+1}, k_{t+1}, i_{t}, b_{t+1}, \mu_{t}\right\}_{t=0}^{\infty}$ using the following equations:

$$
\begin{aligned}
U^{\prime}\left(x_{t}\right) & =\frac{A}{W_{t}} \\
1 & =\beta E_{t}\left[\frac{U^{\prime}\left(x_{t+1}\right)}{U^{\prime}\left(x_{t}\right)} \frac{R_{t}}{\pi_{t+1}}\right] \\
1 & =\mu_{t}\left[1-S\left(\frac{i_{t}}{i_{t-1}}\right)+\frac{i_{t}}{i_{t-1}} S^{\prime}\left(\frac{i_{t}}{i_{t-1}}\right)\right]+\beta E_{t}\left\{\frac{U^{\prime}\left(x_{t+1}\right)}{U^{\prime}\left(x_{t}\right)} \mu_{t+1}\left(\frac{i_{t+1}}{i_{t}}\right)^{2} S^{\prime}\left(\frac{i_{t+1}}{i_{t}}\right)\right\} \\
k_{t+1} & =(1-\delta) k_{t}+\left[1-S\left(\frac{i_{t}}{i_{t-1}}\right)\right] i_{t} \\
\mu_{t} & =\beta E_{t}\left[\frac{U^{\prime}\left(x_{t+1}\right)}{U^{\prime}\left(x_{t}\right)}\left[R_{t+1}^{k}+(1-\delta) \mu_{t+1}\right]-\frac{\sigma}{U^{\prime}\left(x_{t}\right)} \gamma\left(q_{t+1}, k_{t+1}, \chi_{t+1}, Z_{t+1}\right)\right] \\
\frac{m_{t}}{P_{t}} & =\frac{g\left(q_{t}, k_{t}, \chi_{t}, Z_{t}\right) W_{t}}{A} \\
1 & =\beta E_{t}\left\{\frac{U^{\prime}\left(x_{t+1}\right)}{U^{\prime}\left(x_{t}\right) \pi_{t+1}}\left[\frac{\sigma \chi_{t+1} u^{\prime}\left(q_{t+1}\right)}{g_{q}\left(q_{t+1}, k_{t+1}, \chi_{t+1}, Z_{t+1}\right)}+(1-\sigma)\right]\right\}
\end{aligned}
$$


where we used $\pi_{t+1} \equiv P_{t+1} / P_{t}$. The first four equations above are entirely standard in a DSGE model with an investment adjustment cost and quasi-linear preferences. Equation (12) is a labor supply equation that relates the wage to the marginal rate of substitution between consumption and leisure. Equation (13) is the Euler equation for bond holdings. Equation (14) describes the evolution of the shadow price of installed capital, $\mu_{t}$, and (15) is the capital accumulation equation.

Equations (16), (17) and (18) reflect the presence of the decentralized market. Equation (16) is the Euler equation for capital stock holdings. The return to capital has two components: the return from renting capital to intermediate good producing firms in the centralized market, $R_{t}^{k}$, net of capital depreciation, and the return to capital when producing in the decentralized market. In the absence of the latter, (16) would be the standard intertemporal Euler equation for capital. The additional term captures the marginal utility of using capital in the DM as a seller which depends on the $\gamma($.$) function defined in (8). Equation (17)$ determines the output produced in the DM, given the pre-determined money balances of the buyer and capital holdings of the seller, among other things.

Finally, (18) is the Euler equation for holding money where the term in square brackets reflects the additional consumption provided in the DM by holding money. In particular, bringing in one more unit of money to the DM of $t+1$ will change the price that the buyer is facing by a fraction $U^{\prime}(.) / g_{q}($.$) due to the$ non-competitive nature of pricing and this will result in increased utility given by the first part of this term which is reached with probability $\sigma$. With probability $1-\sigma$, the extra money is not used in the DM and can be used for consumption in the CM of $t+1$. Note that combining (12), (17) and (18) we obtain the following equation that defines money demand in this environment.

$$
\frac{m_{t+1}}{P_{t}}=\frac{\beta}{U^{\prime}\left(x_{t}\right)} E_{t}\left[g\left(q_{t+1}, k_{t+1}, \chi_{t+1}, Z_{t+1}\right)\left[\frac{\sigma \chi_{t+1} u^{\prime}\left(q_{t+1}\right)}{g_{q}\left(q_{t+1}, k_{t+1}, \chi_{t+1}, Z_{t+1}\right)}+(1-\sigma)\right]\right] .
$$

The two holdup problems discussed in detail in AWW are also present in the bargaining version of our model. In a nutshell, for an interior value of $\theta$, the buyer and the seller both receive a part of the surplus created by their match. However, assuming $R>1$, both have made a costly and irreversible ex-ante investment decision in the previous period: the buyer brought in money and the seller brought in capital. The ex-post split of the surplus creates a double holdup problem. The money-demand holdup problem can be eliminated if $\theta=1$, i.e., when the buyer gets all of the surplus but there is no $\theta$ that can eliminate both problems. ${ }^{7}$ These holdup problems, which are intrinsically linked to the monetary nature of exchange in the DM, will create an extra layer of inefficiency in our policy analysis.

\footnotetext{
${ }^{7}$ See AWW and Aruoba, Rocheteau and Waller (2007) for further details.
} 
Turning to the price-taking version, we need to replace Equations (16), (17), and (18) by

$$
\begin{aligned}
\mu_{t} & =\beta E_{t}\left[\frac{U^{\prime}\left(x_{t+1}\right)}{U^{\prime}\left(x_{t}\right)}\left[R_{t+1}^{k}+(1-\delta) \mu_{t+1}\right]-\frac{\sigma}{U^{\prime}\left(x_{t}\right)} c_{k}\left(q_{t+1}, k_{t+1}, Z_{t+1}\right)\right] \\
\frac{m_{t}}{P_{t}} & =\frac{q_{t} c_{q}\left(q_{t}, k_{t}, Z_{t}\right) W_{t}}{A} \\
1 & =\beta E_{t}\left\{\frac{U^{\prime}\left(x_{t+1}\right)}{U^{\prime}\left(x_{t}\right) \pi_{t+1}}\left[\frac{\sigma \chi_{t+1} u^{\prime}\left(q_{t+1}\right)}{c_{q}\left(q_{t+1}, k_{t+1}, Z_{t+1}\right)}+(1-\sigma)\right]\right\}
\end{aligned}
$$

The changes in (21) and (22) reflect the competitive flavor of pricing in the DM. Increasing the capital stock now simply increases utility by $-\sigma c_{k}($.$) , which is the reduction in the DM cost when the household is a$ seller. The terms of trade are not affected and the extra terms in (8) do not appear.

The set of equations above determines the path of money balances, given $m_{0}$, which is identical across all households assuming an interior solution. As all households start period $t$ with the same money balances, $m_{t}=M_{t}$ where $M_{t}$ is the aggregate money stock, the buyers in the DM enter the CM with $\hat{m}=0$, the sellers with $\hat{m}=2 M$ while the remaining $1-2 \sigma$ households carry $\hat{m}=M$. Looking at (1), this means that individual labor supply depends on the status of the agent in the previous DM as the money holdings. In particular, we have

$$
h_{t}=\left\{\begin{array}{cc}
H_{t}+\frac{\left(M_{t}-0\right)}{P_{t} W_{t}} & \text { buyers } \\
H_{t}+\frac{\left(M_{t}-2 M_{t}\right)}{P_{t} W_{t}} & \text { sellers } \\
H_{t} & \text { others }
\end{array}\right.
$$

where $H_{t}$ is aggregate hours which we define below. This shows that buyers in the DM work more than others since they have to make up for the money they have spent and sellers work less than others. We only care about total hours $H_{t}$ in equilibrium and will not track individual $h_{t}$, or its dispersion.

\subsection{Firms in the Centralized Market}

The setup of the centralized market resembles that of a New Keynesian DSGE model. Production is carried out by two types of firms in the CM: final good producers combine differentiated intermediate goods. Intermediate goods producing firms hire labor and capital services from the households to produce the inputs for the final good producers. To introduce nominal rigidity we follow Calvo (1983) by assuming that only a constant fraction of the intermediate goods producers is able to re-optimize prices.

\subsubsection{Final Good Producers}

The final good $Y_{t}$ in the CM is a composite made of a continuum of intermediate goods $Y_{t}(i)$ :

$$
Y_{t}=\left[\int_{0}^{1} Y_{t}(i)^{\frac{1}{1+\lambda}} d i\right]^{1+\lambda} .
$$


with elasticity of substitution $(1+\lambda) / \lambda$. We constrain $\lambda \in[0, \infty)$. The final good producers buy the intermediate goods on the market, package them into $Y_{t}$ units of the composite good, and resell them to consumers. These firms maximize profits in a perfectly competitive environment taking $P_{t}(i)$ as given, which yields the demand for good $i$

$$
Y_{t}(i)=\left(\frac{P_{t}(i)}{P_{t}}\right)^{-\frac{1+\lambda}{\lambda}} Y_{t}
$$

Combining this condition with the zero profit condition one obtains the following expression for the price of the composite good

$$
P_{t}=\left[\int_{0}^{1} P_{t}(i)^{-\frac{1}{\lambda}} d i\right]^{-\lambda}
$$

\subsubsection{Intermediate Goods Producers and Inflation Dynamics}

Intermediate goods producers, indexed by $i$, use the following Cobb-Douglas technology with fixed costs $\mathcal{F}$ :

$$
Y_{t}(i)=\max \left\{Z_{t} K_{t}(i)^{\alpha} H_{t}(i)^{1-\alpha}-\mathcal{F}, 0\right\} .
$$

The technology shock $Z_{t}$ is identical to the one that appears in the DM production function. Firm $i$ 's profit is given by:

$$
\Pi_{t}(i)=P_{t}(i) Y_{t}(i)-P_{t} W_{t} H_{t}(i)-P_{t} R_{t}^{k} K_{t}(i) .
$$

All firms take factor prices $W_{t}$ and $R_{t}^{k}$, as well as the prices of the other firms and the aggregate price level as given. The cost-minimizing choice of factor inputs leads to the following expression for marginal costs

$$
M C_{t}=\alpha^{-\alpha}(1-\alpha)^{-(1-\alpha)} W_{t}^{1-\alpha}\left(R_{t}^{k}\right)^{\alpha} Z_{t}^{-1} .
$$

Following Calvo (1983), we assume that firms are only able with probability $1-\zeta$ to re-optimize their price in the current period. Firms that are not allowed to choose $P_{t}(i)$ optimally, update their price according to the geometric weighted average of the fixed rate $\pi_{* *}$ and of last period's inflation $\pi_{t-1}$ with weights $1-\iota$ and $\iota$, respectively. In Calvo's original setup $\pi_{* *}=1$ and $\iota=0$. In our empirical analysis we fix $\pi_{* *}=1$ and treat the degree of dynamic indexation, $\iota$, as a parameter to be estimated. It is useful to define the price adjustment factor of a firm in $t+s$, which was able to choose an optimal price in period $t$

$$
\pi_{t+s \mid t}^{a d j}=\prod_{l=1}^{s} \pi_{t+l-1}^{\iota} \pi_{* *}^{1-\iota},
$$

adopting the convention that $\pi_{t \mid t}^{a d j}=1$. Firms that are unable to re-optimize their prices simply satisfy the demand for their product according to (25).

For those firms that are allowed to re-optimize prices, the problem is to choose a price level $P_{t}^{o}(i)$ that maximizes the expected present discounted value of profits in all future states in which the firm is unable to 
re-optimize its price:

$$
\begin{array}{ll}
\max _{P_{t}^{o}(i)} & \mathbb{E}_{t}\left[\sum_{s=0}^{\infty} \zeta^{s} \beta^{s} \Xi_{t+s \mid t}^{p}\left[P_{t}^{o}(i) \pi_{t+s \mid t}^{a d j}-P_{t+s} M C_{t+s}\right] Y_{t+s}(i)\right] \\
\text { s.t. } & Y_{t+s}(i)=\left[\frac{P_{t}^{o}(i) \pi_{t+s \mid t}^{a d j}}{P_{t+s}}\right]^{-\frac{1+\lambda}{\lambda}} Y_{t+s},
\end{array}
$$

where $\beta^{s} \Xi_{t+s \mid t}^{p}$ is the time $t$ value of a dollar in period $t+s$ for the consumers. Here we are considering only the symmetric equilibrium in which all firms that can re-adjust prices will choose the same $P_{t}^{o}(i)$.

The solution of (30) leads to a dynamic relationship between the optimal price $p_{t}^{o}=P_{t}^{o} / P_{t}$ and marginal costs $M C_{t}$. From (26) it follows that

$$
\pi_{t}=\left[(1-\zeta)\left(\pi_{t} p_{t}^{o}\right)^{-\frac{1}{\lambda}}+\zeta\left(\pi_{t-1}^{\iota} \pi_{* *}^{1-\iota}\right)^{-\frac{1}{\lambda}}\right]^{-\lambda},
$$

which links inflation to marginal costs and generates the so-called New Keynesian Phillips curve.

\subsection{Goverment Spending and Fiscal Policy}

In period $t$, the government in this model collects a nominal lump-sum tax $T_{t}$, spends $G_{t}$ on goods from the centralized market, issues one-period nominal bonds $B_{t+1}$ that pay $R_{t}$ gross interest tomorrow and supplies the money to maintain the interest rate rule. It satisfies the following budget constraint every period

$$
P_{t} G_{t}+R_{t-1} B_{t}+M_{t}=T_{t}+B_{t+1}+M_{t+1}
$$

We assume that government spending $G_{t}$ evolves exogenously and will provide further details below.

\subsection{Aggregate Resource Constraint and National Accounting}

We begin by adding the households' CM budget constraints and the government budget constraint to obtain

$$
P_{t} X_{t}+P_{t} I_{t}+P_{t} G_{t}=P_{t} W_{t} H_{t}+P_{t} R_{t}^{k} K_{t}+\Pi_{t}
$$

Now consider intermediate goods producers' profits in the CM

$$
\begin{aligned}
\Pi_{t} & =\int P_{t}(i) Y_{t}(i) d i-P_{t} W_{t} \int H_{t}(i) d i-P_{t} R_{t}^{k} \int K_{t}(i) d i \\
& =P_{t} Y_{t}-P_{t} W_{t} H_{t}-P_{t} R_{t}^{k} K_{t} .
\end{aligned}
$$

The second equality follows from the zero profit conditions for the final goods producers. Combining the expression for profits with (33) we obtain

$$
X_{t}+I_{t}+G_{t}=Y_{t}
$$


which is the resource constraint in the CM. Since there is no savings in the DM (and goods are perishable), there is a trivial resource constraint that sets consumption equal to output.

The relationship between the total output of the intermediate goods producers, $\bar{Y}_{t}$, and the aggregate labor and capital inputs in the CM is given by

$$
\bar{Y}_{t}=Z_{t} \int K_{t}^{\alpha}(i) H_{t}^{1-\alpha}(i) d i-\mathcal{F}=Z_{t} K_{t}^{\alpha} H_{t}^{1-\alpha}-\mathcal{F} .
$$

The second equality follows from the fact that the optimal capital labor ratio $K_{t}(i) / H_{t}(i)$ only depends on relative factor prices that are common to all firms. The quantity of final goods in the CM is related to $\bar{Y}_{t}$ according to

$$
Y_{t}=\frac{1}{D_{t}} \bar{Y}_{t}, \quad D_{t}=\int\left(\frac{P_{t}(i)}{P_{t}}\right)^{-\frac{1+\lambda}{\lambda}} d i
$$

where $D_{t}$ measures the extent of price dispersion and evolves according to

$$
D_{t}=\zeta\left[\left(\frac{\pi_{t-1}}{\pi_{t}}\right)^{\iota}\left(\frac{\pi_{* *}}{\pi_{t}}\right)^{(1-\iota)}\right]^{-\frac{1+\lambda}{\lambda}} D_{t-1}+(1-\zeta)\left[\frac{P_{t}^{o}}{P_{t}}\right]^{-\frac{1+\lambda}{\lambda}} .
$$

Unless $P_{t}(i)=P_{t}$ for all firms, $D_{t}$ will be greater than unity, which in turn implies the economy will produce inside its production possibilities frontier.

We now turn to the aggregation of CM and DM output. Real output in the CM is given by $Y_{t}$ and $P_{t}$ is the price (in terms of money) of the CM final good. Real and nominal output in the DM are given by $\sigma q_{t}$ and $\sigma M_{t}$, respectively. Hence, we can define the price level and inflation in the DM as

$$
P_{t}^{D M}=M_{t} / q_{t}, \quad \pi_{t}^{D M}=P_{t}^{D M} / P_{t-1}^{D M} .
$$

Using the final good produced in the CM as numeraire, we can express total output in the model economy as

$$
\mathcal{Y}_{t}=Y_{t}+\sigma \mathcal{M}_{t} / \pi_{t}
$$

where $\mathcal{M}_{t} \equiv M_{t} / P_{t-1}$ is the real money stock in terms of CM output. To take our model to the data we now construct a GDP deflator and a measure of real GDP that is consistent with this GDP deflator. Following NIPA conventions, we use a Fisher price index. However, to simplify the analysis we replace time-varying nominal shares by steady state shares. The DM share of nominal output in the steady state is $s_{*}=\sigma \mathcal{M}_{*} /\left(Y_{*} \pi_{*}+\sigma \mathcal{M}_{*}\right)$. Thus,

$$
\pi_{t}^{G D P}=\pi_{t}^{1-s_{*}}\left(\pi_{t}^{D M}\right)^{s_{*}} .
$$

Defining real GDP as

$$
\mathcal{Y}_{t}^{G D P}=\mathcal{Y}_{t} \frac{P_{t}}{P_{t}^{G D P}}
$$

we verify in the appendix that up to a first-order approximation changes in real GDP evolve according to

$$
\Delta \ln \mathcal{Y}_{t}^{G D P}=\left(1-s_{*}\right) \Delta \ln Y_{t}+s_{*} \Delta \ln q_{t} .
$$




\subsection{Monetary Policy}

Following authors like Sargent (1999) and Lucas (2000) we assume that low frequency movements of inflation, such as the rise of inflation in the 1970s and the subsequent disinflation episode in the early 1980s, can be attributed to monetary policy changes. Unlike in the learning models considered by Sargent, Williams, and Zha (2006) or Primiceri (2006), our DSGE models offer no explanation why monetary policy shifts occur over time. We simply assume that the target inflation rate $\pi_{*, t}$ is time-varying. The central bank supplies money to control the nominal interest rate. Following the setup in Schorfheide (2005), we assume that it systematically reacts to inflation and output growth according to the rule

$$
R_{t}=R_{*, t}^{1-\rho_{R}} R_{t-1}^{\rho_{R}} \exp \left\{\sigma_{R} \epsilon_{R, t}\right\}, \quad R_{*, t}=\left(r_{*} \pi_{*, t}\right)\left(\frac{\pi_{t}^{G D P}}{\pi_{*, t}}\right)^{\psi_{1}}\left(\frac{Y_{t}^{G D P}}{\gamma Y_{t-1}^{G D P}}\right)^{\psi_{2}}
$$

where $r_{*}$ is the steady state real interest rate, $\gamma$ is the gross steady state growth rate of the economy, and $\epsilon_{R, t}$ is a monetary policy shock that captures transitory deviations from the interest rate feedback rule that are unanticipated by the public.

\subsection{Aggregate Shocks}

We consider five aggregate disturbances in our model economy. $Z_{t}$ is the random productivity term that affects production in both CM and DM. $g_{t}$ is a shock that shifts government spending according to

$$
G_{t}=\left(1-1 / g_{t}\right) \mathcal{Y}_{t}
$$

We assume that although government consumption goods are purchased in the centralized market, the overall amount is a stochastic fraction of total GDP, expressed in CM prices. The money demand shock $\chi_{t}$ shifts preferences for goods produced in the DM. Finally, our model has two monetary policy shocks: $\epsilon_{R, t}$ is assumed to be serially uncorrelated and captures short-run shifts in monetary policy, whereas the time-varying inflation target $\pi_{*, t}$ captures long-run policy changes. We define

$$
\tilde{Z}_{t}=\ln \left(Z_{t} / Z_{*}\right), \quad \tilde{\chi}_{t}=\ln \left(\chi_{t} / \chi_{*}\right), \quad \tilde{g}_{t}=\ln \left(g_{t} / g_{*}\right), \quad \tilde{\pi}_{*, t}=\ln \left(\pi_{*, t} / \pi_{*}\right)
$$

where $Z_{*}, \chi_{*}, g_{*}$, and $\pi_{*}$ are steady state values of the exogenous disturbances. We assume that all the exogenous disturbances except for $\tilde{\pi}_{*, t}$ evolve according to stationary $\operatorname{AR}(1)$ processes

$$
\tilde{Z}_{t}=\rho_{z} \tilde{Z}_{t-1}+\sigma_{z} \epsilon_{z, t}, \quad \tilde{\chi}_{t}=\rho_{\chi} \tilde{\chi}_{t-1}+\sigma_{\chi} \epsilon_{\chi, t}^{\chi}, \quad \tilde{g}_{t}=\rho_{g} \tilde{g}_{t-1}+\sigma_{g} \epsilon_{g, t}
$$

and $\tilde{\pi}_{*, t}$ evolves as a random walk

$$
\tilde{\pi}_{*, t}=\tilde{\pi}_{*, t-1}+\sigma_{\pi} \epsilon_{\pi, t}^{\pi} .
$$


The innovations are stacked in the vector $\epsilon=\left[\epsilon_{z, t}, \epsilon_{\chi, t}, \epsilon_{g, t}, \epsilon_{\pi, t}, \epsilon_{R, t}\right]$ which follows a multi-variate standard normal distribution. The law of motion for the exogenous processes completes the specification of our DSGE model. The equilibrium conditions are summarized in the Appendix. We derive the deterministic steady state for this model and use a log-linear approximation to its dynamics to form a state-space representation that is used for the Bayesian estimation. We log-linearize our model around a $\pi_{*}$ that corresponds to an annual inflation rate of $4 \%$, which is the mean in our sample. AWW use a nonlinear solution scheme (projection method with Chebyshev polynomials) with no shocks and find that around a reasonable neighborhood of the steady state the decision rules are well-approximated linearly. Aruoba and Chugh (2008) use a version of the AWW model with shocks and report that first- and second-order linear approximations and non-linear approximations lead to very similar results. Accumulated evidence from estimating New Keynesian DSGE models, see for example, An (2007), also suggests that first-order approximations work well.

\section{Empirical Analysis}

We now turn to the DSGE model estimation. We use a Bayesian approach discussed in detail in An and Schorfheide (2007). Our data set is described in Section 3.1. For reasons explained below the target inflation rate is treated as an observable in the estimation. The construction of this series is discussed in Section 3.2. Functional forms are specified in Section 3.3 and a description of the prior distribution is provided in Section 3.4. Next, parameter estimates as well as implied steady states are presented in Section 3.5 and the implied model dynamics are analyzed via variance decompositions and impulse response functions in Section 3.6. Finally, we assess the fit of the search-based DSGE model in Section 3.7.

\subsection{Data}

Our empirical analysis is based on quarterly U.S. postwar data on aggregate output, inflation, interest rates, (inverse) velocity of money, and a measure of the central bank's target inflation rate. Unless otherwise noted, the data are obtained from the FRED2 database maintained by the Federal Reserve Bank of St. Louis. Per capita output is defined as real GDP (GDPC96) divided by civilian non-institutionalized population (CNP16OV). The population series is provided at a monthly frequency and converted to quarterly frequency by simple averaging. Since the quarterly flow statistics reported in the National Income and Product Accounts are annualized, we divide real GDP by 4 . The model presented in Section 2 is specified to capture stationary fluctuations around a deterministic steady state. Hence, we take the natural log of per capita output and extract a deterministic trend by an OLS regression over the sample period 1959:I to 2006:IV. The deviations from the linear trend are scaled by 100 to convert them into percentages. 
Inflation is defined as the log difference of the GDP deflator (GDPDEF) and multiplied by 400 to obtain annualized percentages. Our measure of nominal interest rates corresponds to the federal funds rate (FEDFUNDS). The federal funds rate is provided at monthly frequency and converted to quarterly frequency by simple averaging. Money is incorporated as an observable by using inverse M1 velocity. We use the sweepadjusted M1S series provided by Cynamon, Dutkowsky and Jones (2006). ${ }^{8}$ This series is recorded at monthly frequency without seasonal adjustments. The EVIEWS default version of the X12 filter is applied to remove seasonal variation. The M1S series is divided by quarterly nominal output to obtain inverse velocity. Since the choice variable $M_{t+1}$ in our model corresponds to the money balances at the end of period $t$, velocity in period $t$ is computed based on the money stock in the last month of the quarter. We take the natural $\log$ of inverse velocity, and scale it by 100 to relate it to the $\log$ deviations from $100 * \ln \left(\mathcal{M}^{*} / \mathcal{Y}^{*}\right)$. Our estimation sample ranges from 1965:I to 2005:I and we use likelihood functions conditional on data from 1964:I to 1964:IV to estimate our DSGE model and vector autoregressions (VARs).

\subsection{Target Inflation and Velocity}

As explained in Section 2, we assume that the target-inflation rate $\pi_{*, t}$ is time varying. One could simply treat $\pi_{*, t}$ as a latent variable in the likelihood-based estimation of the DSGE model and use the Kalman smoother to obtain ex-post estimates of $\pi_{*, t}$ based on the observations that are included in the construction of the likelihood function. We shall deviate from this commonly used approach for the following two reasons: (i) we will assess the time series fit of the DSGE model and the propagation of unanticipated changes in the target inflation rate through a comparison with a VAR. To facilitate this comparison, it is helpful to treat the target inflation rate as observable. (ii) From the perspective of the agents $\pi_{*, t}$ can be interpreted as a long-run inflation expectation. Hence, we will incorporate survey expectations in the construction of the $\pi_{*, t}$ series.

The first step of our analysis is to apply a bandpass filter to the GDP deflator inflation rate. Since the agents generate forecasts of future target inflation rates with a random walk model we will use a one-sided bandpass filter that removes cycles of a duration of less than 64 quarters. Our filter is based on the approach by Geweke (1978) and Pierce (1980). We construct a time-domain moving average representation of the ideal one-sided filter (truncated at 500 lags) and then replace missing lagged observations by optimal backcasts obtained from an estimated AR(4) model. The resulting filtered inflation series is plotted in the top left panel of Figure 1. The panel also shows 1-year and 10-year-ahead inflation expectations obtained from the Survey of Professional Forecasters, maintained by the Federal Reserve Bank of Philadelphia. From 1972 to

\footnotetext{
${ }^{8}$ Since mid-1990s, banks in the U.S. regularly "swept" funds from their customers checking accounts to money market accounts in an effort to avoid holding reserves, significantly distorting the money measures. Since this was typically done in a fashion invisible to the account holders, we use this measure which adjusts M1 as explained in Cynamon et al. (2006).
} 
1985 as well as from 1995 to 2005 these three measures of target inflation move closely together. Only from 1990 to 1995 there is a discrepancy between the bandpass filtered series and the inflation expectations that exceeds 150 basis points.

To combine the three series we use a small state-space model with measurement equations

$$
\tilde{\pi}_{t}^{B P}=\widetilde{\pi}_{*, t}+0.025 \epsilon_{1, t}, \quad \tilde{\pi}_{t}^{1 y}=\widetilde{\pi}_{*, t}+\eta_{2, t}, \quad \tilde{\pi}_{t}^{10 y}=\widetilde{\pi}_{*, t}+\eta_{3, t},
$$

and state transitions

$$
\tilde{\pi}_{*, t}=\widetilde{\pi}_{*, t-1}+\sigma_{\pi} \epsilon_{\pi, t}, \quad \eta_{2, t}=\rho_{2} \eta_{2, t-1}+\sigma_{2} \epsilon_{2, t}, \quad \eta_{3, t}=\rho_{3} \eta_{3, t-1}+\sigma_{3} \epsilon_{3, t},
$$

where the $\epsilon_{i, t}$ 's are iid standard normal random variables and $\widetilde{\pi}_{t}^{B P}, \widetilde{\pi}_{t}^{1 y}$, and $\widetilde{\pi}_{t}^{10 y}$ are bandpass filtered inflation, 1-year-ahead forecasts, and 10-year-ahead forecasts, respectively. We fixed the innovation standard deviation for $\widetilde{\pi}_{t}^{B P}$ to implicitly control the weight on the bandpass filtered series and estimated the remaining parameters. The filtered target inflation series $\widetilde{\pi}_{*, t}$ is displayed in the top right panel of Figure 1 together with the GDP deflator inflation. If one regresses the filtered series $\widetilde{\pi}_{*, t}$ on the three observed measures, the coefficients are $0.57\left(\widetilde{\pi}_{t}^{B P}\right), 0.22\left(\widetilde{\pi}_{t}^{1 y}\right)$, and $0.23\left(\widetilde{\pi}_{t}^{10 y}\right)$. Moreover, the dynamics of $\widetilde{\pi}_{*, t}$ are well approximated by the random walk that the DSGE model agents use to forecast the target inflation rate.

Finally, the bottom panel of Figure 1 overlays the federal funds rate and M1 inverse velocity. According to our theoretical framework, the rise and fall of the nominal interest rate is to a large extent generated by exogenously changing preferences of monetary policy makers, as reflected in $\pi_{*, t}$. The postwar U.S. data exhibit a strong negative correlation between inverse velocity and nominal interest rates that at least qualitatively resembles a money-demand relationship.

\subsection{Functional Forms}

We use the following functional forms in our estimation:

$$
u(q)=\ln (q+\kappa)-\ln (\kappa), \quad U(x)=B \ln (x), \quad f(e, k)=e^{1-\alpha} k^{\alpha},
$$

where $\kappa$ is set equal to $1 \mathrm{E}-4$ to make sure $q_{t}=0$ can be handled. ${ }^{9}$ The parameter $B$ determines the relative weight of the utility from consuming the CM and DM goods. We use a natural logarithm for both utility functions and use the same Cobb-Douglas production function as the function used by the intermediate good producers in the CM as these are necessary conditions for balanced-growth in this model, as Waller (2009) shows. The functional form assumption for $f(e, k)$ implies that

$$
c(q, k, Z)=\frac{1}{Z^{1 /(1-\alpha)}} q^{1 /(1-\alpha)} k^{-\alpha /(1-\alpha)} .
$$

\footnotetext{
${ }^{9}$ In the bargaining problem in the DM, the threat point of a buyer is having $q=0$ and moving on to the next CM. With this functional form $u(0)=0$ and this threat point is well-defined.
} 


\subsection{Restricted Parameters and Prior Distributions}

One goal of our empirical analysis is to compare the propagation of shocks and the steady state welfare implications for various specifications of our model. Hence, it is desirable to normalize and restrict a subset of the model parameters prior to estimation. A summary is provided in Table 1. The steady states of real GDP, $\mathcal{Y}_{*}$, and the DM preference shock process, $\chi_{*}$, are normalized to one. The steady state log inverse velocity is fixed at the sample mean -0.38. Average inverse labor productivity in our sample is 0.03 (a worker produces about $\$ 33$ of real GDP in one hour) and we use this value to restrict $H_{*} / Y_{*}$. These restrictions imply unique values for the the preference parameters $A$ and $B$ as well as the steady state level of technology $Z_{*}$.

We log-linearize our DSGE model around the average inflation rate in our sample, which is approximately $4 \%$. We let $r_{A}$ be equal to the difference of the average federal funds rate and the average inflation rate between 1965 and 2005 and set $\beta=1 /\left(1+r_{A} / 400\right)$. We set $g_{*}=1.2$, which is computed from the average ratio of government consumption plus investment and GDP. We fix the depreciation rate $\delta$ at 0.014 . This value is obtained as the average ratio of fixed asset depreciation and the stock of fixed assets between 1959 and $2005 .^{10}$

It is well known that the central bank's reaction to inflation deviations, $\psi_{1}$, is difficult to identify. Since the primary focus of the paper is not to estimate monetary policy rules we set $\psi_{1}=1.7$. This value is taken from Schorfheide (2005), who estimated a model with a regime-switching target inflation rate over a similar time period. Finally, we let $\mathcal{F}=0$ (no fixed costs) and $\pi_{* *}=1$, meaning that there is no static indexation for the firms that cannot change their prices.

Suppose we stack the remaining DSGE model parameters in the vector $\vartheta$ with elements $\vartheta_{i}, i=1, \ldots, k$. Our prior distribution for $\vartheta$ takes the form

$$
p(\vartheta) \propto f(\vartheta) \prod_{i=1}^{k} p_{i}\left(\vartheta_{i}\right) .
$$

The marginal densities $p_{i}\left(\vartheta_{i}\right)$ capture prior information for individual parameters and are summarized in the first four columns of Table 2. Following Del Negro and Schorfheide (2008), the function $f(\vartheta)$ is used to incorporate beliefs about steady states that are a function of multiple parameters.

The two household-related parameters are related to the search and matching frictions that generate a role for money demand. We guide our priors for these parameters using the calibration in AWW. Specifically, $\sigma$, the probability of a single coincidence in the DM, is bounded between zero and 0.5 and has a fairly wide prior around 0.2. As we demonstrate further below, this parameter affects the steady state velocity and the

\footnotetext{
${ }^{10}$ We use NIPA-FAT11 (current cost net stock) and NIPA-FAT13 (current cost depreciation) for fixed assets and consumer durables).
} 
responsiveness of money demand to changes in the interest rate. In the bargaining version of our model the parameter $\theta$ measures the bargaining power of the buyer and affects the mark-up in the decentralized market. The prior for the bargaining power is uniform over its range of $[0,1]$.

Turning to the firms, we use a uniform prior on the indexation parameter $\iota$. As we discuss further below and as Schorfheide (2009) argues, previous studies fixed or estimated $\iota$ to be a wide range of numbers, including zero (no dynamic indexation) and one (full dynamic indexation). Our prior for $\zeta$ is broadly consistent with micro-evidence on the frequency of price changes. The parameter $\lambda$ corresponds to the markup in the centralized market and is centered at $15 \%$. The prior distributions for $\rho_{g}, \rho_{z}$, and $\rho_{\chi}$ reflect the belief that the government spending (demand) disturbance, the technology shock, and the DM preference shock are fairly persistent. The priors for the shock standard deviations were loosely chosen such that the implied distribution of the variability of the endogenous variables is broadly in line with the variability of the observed series over a pre-sample from 1959 to 1964.

The function $f(\vartheta)$ summarizes beliefs about the investment-output $\left(I_{*} / \mathcal{Y}_{*}\right)$ ratio, the labor share $(l s h)$, and the mark-ups in the decentralized market $\left(m u_{D M}\right)$ as well as the overall economy $(m u)$ :

$$
f(\vartheta)=\exp \left\{-\frac{1}{2}\left[\frac{\left(I_{*}(\vartheta) / \mathcal{Y}_{*}(\vartheta)-0.16\right)^{2}}{0.005^{2}}+\frac{(l \operatorname{sh}(\vartheta)-0.60)^{2}}{0.01^{2}}+\frac{\left(m u_{D M}(\vartheta)-0.15\right)^{2}}{0.01^{2}}+\frac{(m u(\vartheta)-0.15)^{2}}{0.01^{2}}\right]\right\} .
$$

Thus, $f(\vartheta)$ down-weighs the overall prior density at parameter combinations for which the investment output ratio, the labor share, and the mark-ups deviate from $0.16,0.60$, and 0.15 , respectively. For the price-taking version of the search-based DSGE model the mark-up in the decentralized market is zero and we drop the corresponding term from the function $f(\vartheta)$.

\subsection{Parameter and Steady State Estimates}

The posterior distribution is obtained by combining the prior distribution described in the previous subsection with the likelihood function for output, inflation, interest rates, inverse velocity, and the target inflation rate derived from the state-space representations of the linearized DSGE models. We then use a random-walk Metropolis algorithm to generate draws from the posterior distribution of the parameters. To make inference about steady states, impulse responses, and variance decompositions, we convert the parameter draws into the statistics of interest. Further technical details are described in An and Schorfheide (2007). Posterior means and 90\% credible intervals for the estimated DSGE model parameters are reported in Table 2. The bargaining model is abbreviated as $\operatorname{SBM}(\mathrm{B})$ and the price-taking model as $\mathrm{SBM}(\mathrm{PT})$.

The estimated single-coincidence probability is around 0.3. We will document in Section 3.7 that this estimate captures the fairly low short-run elasticity of money demand with respect to interest rates in the data. The estimate of $\theta=0.95$ in $\operatorname{SBM}(B)$ is strongly influenced by the prior distribution that favors 
parameter values consistent with a mark-up of about $15 \%$ throughout the sectors of the economy. This leads to a DM mark-up of $17 \%$ and this along with the $14 \%$ mark-up in the CM and the DM share of $20 \%$ matches our target of aggregate markup. To provide a comparison, in AWW, $\theta$ was calibrated to be around 0.90 using a DM markup of $30 \%$ as the target. ${ }^{11}$

Turning to the firms we have a number of departures from standard parameter estimates due to both the two-sector structure of our model and the differences in pricing mechanisms in the two sectors. The estimate of the CM mark-up is higher in the price taking model, because the DM mark-up is zero and we are using a fairly tight prior that implies an economy-wide mark-up of about $15 \%$. The capital share $\alpha$ is estimated to be significantly larger in $\operatorname{SBM}(B)$ than in $\operatorname{SBM}(\mathrm{PT})$. This is due to the holdup problems in $\operatorname{SBM}(B)$ which, everything equal, reduces the steady state capital stock. Since we are using priors that restrict the investment-output ratio to be approximately $16 \%$ in both models, the hold-up problem present in the bargaining model requires a larger capital share parameter in the production function.

The estimates of the price-stickiness parameter $\zeta$ and the degree of indexation $\iota$ are relatively high in both models, implying an average duration between price re-optimizations in the centralized market of about 6 quarters and a dynamic indexation of 60\%-70\%. In a model in which the rate of static indexation corresponds to the steady state inflation rate, that is $\pi_{* *}=\pi_{*}$, the Phillips curve is given by

$$
\tilde{\pi}_{t}=\frac{\iota}{1+\beta \iota} \widetilde{\pi}_{t-1}+\frac{\beta}{1+\beta \iota} \mathbb{E}_{t}\left[\widetilde{\pi}_{t+1}\right]+\frac{(1-\zeta)(1-\zeta \beta)}{\zeta(1+\beta \iota)} \widetilde{M C}_{t}
$$

Note that we log-linearize our model around $4 \%$ annual inflation and use $\pi_{* *}=1$, which leads to a dynamic Phillips curve where lags of $M C_{t}$ appear. Nevertheless, interpreting our estimates under the restrictions above, our coefficient estimates would translate into a Phillips curve slope of 0.02 (with respect to marginal costs) and the coefficient on lagged inflation would be about 0.42. Compared to the slope estimates surveyed in Schorfheide (2009), which range from 1E-3 to about 4, our estimate is fairly small but not unreasonable. Since the degree of indexation is inherently difficult to identify, the estimates of the coefficient on lagged inflation reported in the literature are essentially uniformly distributed over the range 0 to 0.5 and are very sensitive to auxiliary assumptions about the law of motion of exogenous shocks.

To understand why we obtain a fairly flat Phillips curve and a large degree of dynamic indexation, note that in a standard New Keynesian model $\zeta$ and $\iota$ are identified from the dynamic properties of inflation and the correlation between inflation and marginal cost. For example, if $\iota=0$, then inflation simply inherits the persistence of the sum of discounted expected marginal costs and if $\zeta=0$, there is no Phillips-curve link between inflation and marginal cost fluctuations. In our model, these parameters govern the said properties only for CM inflation and aggregate inflation is a weighted average of the inflation in the CM and the DM. We

\footnotetext{
${ }^{11}$ The steady state growth rate of GDP, which is parameterized by $\gamma$ in the interest rate feedback rule, is set equal to one since we model deviations from the steady state.
} 
will document subsequently that inflation in the DM lacks persistence and prices in the DM are essentially flexible. This means that in order to match the same aggregate properties, CM inflation needs to be more persistent (large $\iota$ ) and CM prices need to be more rigid (large $\zeta$ ). This also means that, in the aggregate, the average duration of a price in our model is in line with other studies that use a one-sector model. The CM firms comprise $80 \%$ of total production, which means the probability that a given price cannot be changed is $0.8 \times 0.83=0.66$. This implies an average duration of 8.8 months between price changes in the aggregate, perfectly in line with other empirical studies.

Table 2 contains two parameters that have not been discussed previously: $\tilde{\pi}_{0, A}^{*}$ is the value of the target inflation process in period $t=0$, measured in deviations from the log-linearization point, which is set to $4 \%$ annualized inflation. The parameter $\sigma_{R, 2}$ measures the standard deviation of the monetary policy shock $\epsilon_{R, t}$ between 1979:I and 1982:IV, a period when interest rate feedback rules are known to fit poorly. The estimates of the parameters that describe the central bank behavior and the evolution of the exogenous shocks are very similar across $\mathrm{SBM}(\mathrm{B})$ and $\mathrm{SBM}(\mathrm{PT})$. The estimated reaction coefficient to output growth is about 0.85 and the interest rate smoothing parameter is 0.6 . The preference shock for DM goods is the most persistent among the shocks with an autocorrelation of about 0.97 .

The implied posterior distribution of the steady states of $\operatorname{SBM}(\mathrm{B})$ and $\operatorname{SBM}(\mathrm{PT})$ is reported in Table 3 . As we explained in Section 3.4, one of our goals in the estimation of our models was to have them display similar long-run characteristics, which are in line with the U.S. postwar experience. Thus, due to our choice of prior distribution the estimated investment-output ratio, capital-output ratio, labor share, and economywide mark-up are very similar across the two model economies. The estimated share of the decentralized market is about $20 \%$. The economies differ, however, with respect to the implied preference parameters $A$ and $B$ and the steady state level of technology $Z_{*}$. Agents in the price-taking economy assign a slightly larger weight to CM consumption and the disutility from working. Moreover, the steady state level of technology is higher in the $\operatorname{SBM}(\mathrm{PT})$ economy. The differences in the $\operatorname{SBM}(\mathrm{B})$ and $\mathrm{SBM}(\mathrm{PT})$ parameter estimates are due to the absence of a hold-up problem under price-taking, and the larger New Keynesian distortion due to a lower estimate of $\iota$.

\subsection{Dynamics}

We now explore the dynamics of our model. Variance decompositions for output, inflation, and interest rates are reported in Table 4. The decompositions are computed for business cycle frequencies ranging from 6 to 32 quarters per cycle. Since the decompositions for $\operatorname{SBM}(B)$ and $\operatorname{SBM}(\mathrm{PT})$ are very similar, we will focus on the bargaining version. Our model was built upon the assumption that the target inflation shock only affects low frequency movements and hence its contribution to business cycle fluctuations is essentially zero. 
Technology shocks cause about $30 \%$ of the output fluctuations and the demand or government spending shocks explain roughly $50 \%$. Technology shocks are also the most important source of inflation dynamics and generate $50 \%$ of its business cycle movements. A part of this last observation is due to the Phillips curve relationship between technology shocks (and therefore marginal costs) and inflation in the CM and a part of it is due to the effect of the technology shock on DM production, which in turn affects inflation in the DM.

A key feature of the search-based models is their non-separable structure, meaning that even under an interest-rate feedback rule, the economy is not insulated from money demand shocks. These money demand shocks arise from time-varying taste for the goods produced in the decentralized market and explain around $5 \%$ of output fluctuations and about $70 \%$ of the cyclical fluctuations of real money balances. This finding is consistent with the central bank accommodating most money demand shocks or a misspecification of our model. While these two interpretations have different implications for policy, we are not able to distinguish between the two in the context of our estimated model.

Impulse response functions to a technology shock for $\mathrm{SBM}(\mathrm{B})$ are depicted in Figure 2. A positive technology shock decreases current and future expected marginal costs. As a result the increase in technology on impact creates an immediate decrease in prices in the DM, which is reflected in the response of DM/CM relative price and DM inflation. Due the rise in productivity, CM and DM production increase on impact. According to the estimated monetary policy rule, the central bank responds to negative inflation and positive GDP growth by lowering the nominal interest rate. The drop in interest rates reduces the opportunity costs of holding money and raises the demand for DM goods and, hence, real money balances. Recall that according to our timing convention time $t$ real money balances reflect end-of-period holdings. As a result of the this increased demand for DM goods,after period 1, DM inflation increases as does CM inflation. CM inflation (not shown) has a typical negative hump-shaped response since Price adjustments in the CM are subject to the Calvo friction. The DM inflation, on the other hand, reacts instantly to shocks and mimics very closely the changes in the interest rate. We consider this to be evidence that DM prices are less sticky than CM prices. Output and consumption in both markets show a hump-shaped response after the shock prolonged by the expansionary policy of the central bank. Since the technology shock is transitory, CM and DM output eventually return to their steady state levels.

Responses to technology shocks in DSGE models tend to be difficult to compare across studies because they are sensitive to assumptions about shock persistence - random-walk versus stationary technology shock - and the central bank's reaction to output fluctuation - reaction to output growth or to deviations of output from a particular measure of potential output. Nonetheless, a comparison with Smets and Wouters (2003, henceforth SW) is instructive. SW estimated a DSGE model with both Calvo price and wage stickiness using a Euro Area data set that included linearly detrended output. They obtain an estimate of $\zeta$ of about 0.9 and an estimate of $\iota$ of 0.48 . According to their estimates (SW, Figure 3) the output response to a positive 
technology shock is hump shaped, with a peak after 5 quarters. Both inflation and the interest rate fall, reaching a trough after 3 periods and then slowly returning to their steady state values. Hours worked also fall after a positive technology shock. We obtain very similar results. Due to the large price stickiness in the CM, hours worked (not shown) fall after a positive technology shock. Thus, we conclude that the output and price dynamics in the CM resemble those of other estimated New Keynesian models. Due to the presence of the DM, in which prices are effectively flexible, our response of aggregate inflation is stronger than in SW, essentially monotonic, and fairly short-lived.

The effect of a shock to preferences for the DM good is depicted in Figure 3. The responses resemble those of a typical demand shock with a shift to the DM and an increase in the relative price of DM goods. On impact DM output cannot change since money balances are pre-determined. Moreover, since money becomes more valuable tomorrow (due to the persistence of the increase in $\chi$ ), DM prices decline on impact. In order to finance higher DM consumption, households accumulate more money, which reduces CM consumption and output initially. Once DM variables start to adjust in period 2, DM inflation shoots up due to increased demand, which triggers the central bank to increase interest rates and stabilize the economy after a few oscillations due to overshooting in both directions. There is a long-lived response of output due almost solely to the persistent increase in DM output.

Finally, responses to a contractionary short-run monetary policy shock are provided in Figure 4. Real GDP and aggregate inflation (at annualized rates) both drop approximately by 50 basis points. Compared to the papers surveyed in Schorfheide (2009) this estimate of the relative output and inflation response is on the high side, albeit not unreasonably large. It indicates that the overall level of nominal rigidity in the model economy, despite the fairly large $\zeta$ estimate for the $\mathrm{CM}$, is small, as we explained above. The rise in the nominal interest rate increases the opportunity costs of holding money and reduces the relative demand for goods produced in the DM as evidenced by the drop in relative prices. After the initial impact, the fall in output and inflation prompts the central bank to lower the interest rate to essentially undo the initial increase, which starts a recovery in both the CM and the DM. After a few oscilations due to the large response of DM inflation and output, the economy converges back to the steady state at a somewhat sluggish pace. A discussion of dynamic responses to a change in the target inflation rate is deferred to the subsequent section.

Before we conclude the discussion of model dynamics, we want to provide some evidence about the lack of persistence of DM inflation, which was key in understanding why $\iota$ is large. Using a simulation of our model, we find that the aggregate inflation has an autocorrelation of between $0.34-0.53$, which is broadly in line with the data, as it should be. This can be decomposed into CM inflation persistence of between $0.74-0.91$ and DM inflation persistence of around -0.10 . 


\subsection{Model Fit}

In order to assess the fit of the estimated search-based DSGE model, we will consider two reference models. The first reference model is a standard New Keynesian DSGE model in which real money balances directly enter the utility function in an additively separable manner. We will refer to this model as the MIU model. The second reference model is a restricted vector autoregression, in which the target inflation rate evolves exogenously. We consider various measures of relative fit, including marginal log likelihood values, insample root-mean-squared errors (RMSE), and discrepancies between the DSGE model and the VAR impulse response functions.

MIU Model: We construct the MIU model by shutting down $(\sigma=0)$ the decentralized market in the search-theoretic models described in Section 2 and adding a real-money balance term to the households' instantaneous utility function:

$$
\mathcal{U}_{t}=U\left(x_{t}\right)-A h_{t}+\frac{\chi_{t}}{1-\nu}\left(\frac{m_{t}}{P_{t}} \frac{A}{Z_{*}^{1 / 1-\alpha}}\right)^{1-\nu}
$$

The shock $\chi_{t}$ captures time-varying preferences for money and the parameter $\nu$ controls the interest-rate elasticity of money demand. The scaling by $A / Z_{*}^{1 /(1-\alpha)}$ can be interpreted as a re-parameterization of $\chi_{t}$, which has the effect that steady state velocity stays constant as we change $A$ and $Z$. To mimic the timing conventions in the search-based models, we assume that $m_{t}$ is the (pre-determined) money stock at the beginning of the period, and $P_{t}$ is the price at which the final good is sold in period $t$. For the common parameters, we impose the same restrictions and use the same prior distributions as in the estimation of $\operatorname{SBM}(\mathrm{B})$ and $\mathrm{SBM}(\mathrm{PT})$. In addition, we assume that the parameter $\nu$ is a priori distributed according to a gamma distribution with mean 20 and variance $5 .{ }^{12}$

VAR: We collect output, inflation, interest rates, and inverse velocity in the $4 \times 1$ vector $y_{1, t}$ and the target inflation rate in the $1 \times 1$ vector $y_{2, t}$. Moreover, we let $y_{t}=\left[y_{1, t}^{\prime}, y_{2, t}\right]^{\prime}$. We assume that $y_{t}$ follows a Gaussian vector autoregressive law of motion subject to the restrictions that the target inflation rate evolves according to a random walk process and that the innovations to the target inflation rate are orthogonal to the remaining shocks. These restrictions are consistent with the assumptions that underlie our DSGE model and identify the propagation of unanticipated changes in the target inflation. The VAR takes the form

$$
\begin{aligned}
& y_{1, t}=\Phi_{0}+\Phi_{1} y_{t-1}+\ldots+\Phi_{2} y_{t-p}+\psi \Delta y_{2, t}+u_{1, t} \\
& y_{2, t}=y_{2, t-1}+\sigma_{\pi_{*}} \epsilon_{\pi_{*}, t}
\end{aligned}
$$

where $u_{1, t} \sim \mathcal{N}\left(0, \Sigma_{11}\right)$ and is independent of $\epsilon_{\pi_{*}, t}$. We estimate the VAR composed of (45) and (46) with

\footnotetext{
${ }^{12}$ Large estimates of this parameter are common in the literature. Levin et al. (2006) report an estimate of 11.4 and Christiano et al. (2005) report 10.6 .
} 
$p=4$ using a version of the "Minnesota" prior (see Doan, Litterman, and Sims (1984) and Sims and Zha (1998)) described in Lubik and Schorfheide (2006). ${ }^{13}$

Log marginal data densities and in-sample RMSEs for $\operatorname{SBM}(\mathrm{B}), \operatorname{SBM}(\mathrm{PT}), \mathrm{MIU}$, and the VAR are reported in Table 5. If two models have equal prior probabilities, then differences of log marginal data densities can be interpreted as log posterior odds. Moreover, since for any model with a $k$ dimensional parameter vector $\theta$

$$
\ln p\left(Y^{T}\right)=\sum_{t=1}^{T} \ln p\left(y_{t} \mid Y^{t-1}\right)=\sum_{t=1}^{T} \ln \int p\left(y_{t} \mid \theta, Y^{t-1}\right) p\left(\theta \mid Y^{t-1}\right) d \theta
$$

where $Y^{t}$ collects $y_{1}, \ldots, y_{t-1}$ and $Y^{0}$ signifies prior information, log marginal likelihoods can be interpreted as pseudo-out-of-sample one-step-ahead predictive scores. Finally, the approximation

$$
\begin{aligned}
\ln p\left(Y^{T}\right) & =\ln \int p\left(Y^{T} \mid \theta\right) p(\theta) d \theta \approx \ln p\left(Y^{T} \mid \hat{\theta}_{T}\right)+\ln p\left(\hat{\theta}_{T}\right)+\ln \int \exp \left\{-\frac{1}{2}\left(\theta-\hat{\theta}_{T}\right)^{\prime} \hat{H}\left(\theta-\hat{\theta}_{T}\right)\right\} d \theta \\
& \approx \ln p\left(Y^{T} \mid \hat{\theta}_{T}\right)+\ln p\left(\hat{\theta}_{T}\right)+\frac{k}{2} \ln (2 \pi)+\frac{1}{2} \ln \left|\hat{H}_{T}\right|
\end{aligned}
$$

where $\hat{\theta}_{T}$ is the maximum likelihood estimator (MLE) and $\hat{H}_{T}$ is the Hessian evaluated at the MLE, highlights that the log marginal data density adjusts the maximized log likelihood function by a penalty for model complexity, namely, the log determinant of the Hessian.

According to the log marginal likelihoods, the bargaining version of the SBM is slightly preferred over the price taking version. A comparison of the RMSEs suggests that the ranking is mainly due to differences in the RMSE for inverse velocity. ${ }^{14}$ The MIU model attains an even larger marginal likelihood value than $\operatorname{SBM}(B)$. While the MIU's in-sample output predictions are slightly less precise, the inflation, interest rate, and velocity forecasts are more accurate than those of the search-based models.

The two main differences between the MIU model and the SBMs are that, first, the MIU model only has one sticky-price sector whereas the SBMs are composed of a sticky price and a flexible price sector that are aggregated into GDP. Second, the MIU model has a separable structure that insulates the economy from money demand shocks. We will focus on the latter aspect. The estimated value of $\rho_{\chi}$ in the MIU model is 0.98 and most of the variation in real money is explained by the highly persistent money demand shock $\tilde{\chi}_{t}$, which has no effect on output, inflation, and interest rates. Thus, the weak correlation between real money

\footnotetext{
${ }^{13}$ The Minnesota prior tilts the estimates of the VAR coefficients toward univariate unit root representations. The hyperparameters are $\tau=0.1, d=3.1, w=5, \lambda=1, \mu=1$. Our prior assumes that the elements of $\Psi$ are independently distributed according to $\mathcal{N}\left(0, \lambda^{-2}\right)$.

${ }^{14}$ This and the subsequent statements relating marginal log likelihoods and RMSEs need to be taken with a grain of salt. In a model with normally distributed shocks, $\ln p\left(Y^{T} \mid \hat{\theta}_{T}\right)$ is approximately a function of the log determinant of the in-sample one-step-ahead forecast error covariance matrix. This log determinant does not only depend of the diagonal elements of the forecast error covariance matrix, but also on the off-diagonal elements.
} 
and the other variables in the data allows the money demand shock in the MIU model to capture real money balance fluctuations without compromising the fit for any other variable. In contrast, aggregate output and inflation in the search-based models are not insulated from money demand shocks. ${ }^{15}$ The relative ranking of the MIU model and the search-based models is consistent with Ireland's (2004) finding that when money is included as observable, U.S. data tend to reject non-separabilities in a more general MIU model.

The vector autoregression removes the restrictions that the DSGE models place on the joint dynamics of output, inflation, interest rates, and velocity. As is common in marginal likelihood comparisons between estimated DSGE models and VARs, the VAR dominates $\operatorname{SBM}(B), \operatorname{SBM}(\mathrm{PT})$, and the MIU model by a fairly large margin.

\subsection{Money Demand}

As discussed in detail in Schorfheide (2000), since the VAR attains a better time series fit than the DSGE models, we can use its implications with respect to the propagation of shocks as a benchmark to assess the search-based models. In a typical VAR, identifying structural shocks require assumptions which may not necessarily in line with the assumptions in a DSGE model. In our setup, since we use the same law of motion for the inflation target in both the VAR and the DSGE model and treat it as observable in our DSGE model, the identification in the VAR fit squarely with our assumptions in the DSGE model. Figure 5 depicts impulse responses to a target inflation shock that raises inflation by about 20 basis points in the long run computed from the VAR (dotted bands show 90\% credible sets) and $\operatorname{SBM}(\mathrm{B})$ (solid lines show the posterior mean). The DSGE model restrictions imply that the long-run responses of inflation, nominal interest rates, and target inflation are identical. While the long-run responses of the VAR are unconstrained, the impulse response bands for inflation and interest rates are approximately consistent with a 20-basis-point increase over long horizons.

The most striking discrepancy between VAR and our model responses arises for inverse velocity. According to the VAR, the initial response of inverse velocity is sluggish, but after 20 periods it has fallen 100 basis points below its mean value, whereas the model based responses are a magnitude smaller. The VAR estimates indicate that the interest elasticity of money demand is much lower in the shortrun than in the longrun. According to the posterior mean VAR responses interest rates increase 5 basis points in the first period and velocity drops roughly 10 basis points below its steady state value. After five periods, the interest rate is up 26 basis points and velocity is down 58 basis points. In the longrun, after 200 periods (not shown), the interest rate has increased by 29 basis points, whereas velocity has fallen about 210 basis points.

\footnotetext{
${ }^{15}$ When we produce the filtered signals shutting down all shocks except for the money demand shocks (not shown), in the MIU model output, inflation and the interest rate are completely flat while for our model there are small but non-trivial fluctuations.
} 
As we show below, this discrepancy between the DSGE model and the VAR can be explained by the inability of our DSGE model to match both short- and long-run interest elasticities of money demand. For the $\operatorname{SBM}(\mathrm{PT})$ it is fairly straightforward to derive the log-linear approximation to the money demand function. ${ }^{16}$

$$
\widetilde{\mathcal{M}}_{t+1} \approx-\frac{R_{*}}{\left(R_{*}-1\right)+\sigma} \widetilde{R}_{t}+\mathbb{E}_{t}\left[\widetilde{X}_{t+1}\right]+\mathbb{E}_{t}\left[\widetilde{\pi}_{t+1}\right]+\mathbb{E}_{t}\left[\widetilde{\chi}_{t+1}\right]
$$

where $\widetilde{\mathcal{M}}_{t+1}$ is the real money balance based on end-of-period $t$ money holdings. The interest semi-elasticity is given by $R_{*} /\left(R_{*}-1+\sigma\right)$ which is a decreasing function of $\sigma .{ }^{17}$ According to our posterior estimates, the interest semi-elasticity is about 3 in $\mathrm{SBM}(\mathrm{PT})$. If one interprets the ratio of inverse velocity and interest rate response as interest semi-elasticity, then the short-run elasticity is about 2 and the long-run elasticity roughly 7. These figures are consistent with other numbers that have been reported in the literature. Goldfeld and Sichel (1990) estimate the short-run interest semi-elasticity to be around one. Estimates of the long-run semi-elasticity reported in Lucas (1988, 2000), Stock and Watson (1993), and Ball (2001) range from 5 to 11. It is apparent from Equation (47) that short- and long-run elasticities in our DSGE models are essentially identical. The likelihood-based estimation picks up the low short-run elasticity. In Figure 5, this is reflected in DSGE-model-based velocity responses that are small at all horizons.

Guerron-Quintana (2009) considers a New Keynesian DSGE model in which demand for money arises because of the presence of reduced-form transaction costs. He assumes that in every period only a fraction of households are able to re-optimize their money balances. This arguably ad-hoc mechanism generates an initially sluggish response of velocity to interest rate movements and disentangles short- and long-run interest semi-elasticities of money demand. GMM estimation of the model-implied money demand function based on a sample from 1960 to 2005 yields a short-run elasticity of about one and a long-run elasticity of approximately 13. Moreover, Guerron-Quintana (2009) provides some evidence that the two elasticities have dropped to 0.4 and 5 after 1984 .

Returning to our estimation, Figure 6 depicts the steady state relationship between log inverse velocity and the target inflation rate for $\operatorname{SBM}(\mathrm{B})$ and $\operatorname{SBM}(\mathrm{PT})$ at the posterior mean parameter estimates and provides a scatter plot of U.S. data. According to our estimated search-based models, consistent with the previously presented impulse response function evidence, changes in the target inflation rate have a small effect on inverse velocity. Note that at the steady state the nominal interest rate is given by $R_{*}=\pi_{*} / \beta$. This shows that the elasticity of money demand with respect to the nominal interest rate and that with respect to inflation are identical since the interest rate can change only if there are changes in the inflation target.

\footnotetext{
${ }^{16}$ The expression for $\mathrm{SBM}(\mathrm{PT})$ is approximate because $\mathbb{E}_{t}\left[\widetilde{q}_{t+1}\right]$ enters with a coefficient that is very close to zero but not exactly zero. The same ideas will go through for the bargaining model.

${ }^{17}$ Note that for small interest rates, the elasticity with respect to the gross interest rate is equal to the semi-elasticity with respect to the net interest rate.
} 
In order to capture the large negative relationship between interest rates and inverse velocity in the longrun present in the data, we have to lower $\sigma$ from 0.31 to about 0.06 , which raises the interest semi-elasticity from 3 to 13 in $\operatorname{SBM}(\mathrm{PT}) .{ }^{18}$ That we need to lower $\sigma$ to increase the sensitivity of money demand to changes in the interest rates is obvious from (47). To understand this better recall that the nominal return on a bond is $R_{t}$, whereas the expected nominal return on holding money is

$$
\mathbb{E}_{t}\left[\sigma \frac{\chi_{t+1} u^{\prime}\left(q_{t+1}\right)}{c_{q}\left(q_{t+1}, K_{t+1}, Z_{t+1}\right)}+(1-\sigma)\right]
$$

which depends on the realization of the idiosyncratic taste shock as well as the money demand shock. The term $\chi_{t+1} u^{\prime}\left(q_{t+1}\right)$ captures the marginal utility of consuming $q_{t+1}$ units of the DM good, and $c_{q}$ captures the marginal disutility of producing it. Thus, the smaller the probability of participating in the DM, the more interest rate sensitive the return to holding money conditional on participating in the DM has to be to equate the expected returns on bond and money holdings. Since in equilibrium the return to holding money is (inversely) proportional to money balances, the interest rate elasticity of money demand has to be decreasing in $\sigma$.

Choosing $\sigma$ to match the steady state relationship between interest rates and velocity (as a function of the target inflation rate) to the correlation observed in U.S. data ignores the fact that much of the variation in the actual data is caused by other exogenous shocks. However, if we compare the implied posterior predictive distributions for the correlation between velocity and interest rates conditional on only the target inflation shock, we find that $\sigma=0.06$ yields a very good match between the VAR and DSGE model implied predictive distributions.

To examine the effects of inducing a high long-run interest rate elasticity of money demand we reestimate $\operatorname{SBM}(\mathrm{B})$ and $\mathrm{SBM}(\mathrm{PT})$ subject to the restriction that $\sigma=0.06$. Only the estimates of parameters that govern the dynamics of the money demand shock and the price rigidity in the $\mathrm{CM}$ are significantly affected by lowering $\sigma$. The estimated persistence of $\chi$ drops slightly and the standard deviation $\sigma_{\chi}$ increases dramatically because the velocity forecasts are deteriorating. The implied size of the decentralized market shrinks from $20 \%$ to $4 \%$ of GDP which yields smaller estimates for $\zeta$ and $\iota$. Less price rigidity in the CM is needed to capture the same aggregate inflation dynamics.

The log marginal data density for the two search-based models drops by more than 100 points (see Table 5) and the in-sample RMSE of inverse velocity rises from 2.17 to 3.22 for $\operatorname{SBM}(\mathrm{B})$ and from 2.32 to 3.20 for $\operatorname{SBM}(\mathrm{PT})$. The RMSEs for output, inflation, and interest rates do not change by the same order of magnitude. Thus, imposing a low value of $\sigma$ in the search-based models leads to an unambiguous deterioration of time series fit. We should note that the estimated MIU model is also unable to match the

\footnotetext{
${ }^{18}$ The benchmark annual calibration in AWW, who use long-run observations including the interest elasticity of money demand, uses $\sigma=0.25$. A quarterly calibration, which is comparable to our estimation, yields exactly $\sigma=0.06$.
} 
long-run interest elasticity of money demand. We also re-estimated the MIU model subject to the high elasticity restriction $\nu=5.15$, which implies an increase of the interest semi-elasticity from 2 to 12 , and found a similar deterioration in fit as for $\operatorname{SBM}(B)$ and $\operatorname{SBM}(\mathrm{PT})$.

Going back to Figure 5, we also show the posterior mean impulse response to an inflation target shock from the restricted version of $\mathrm{SBM}(\mathrm{B})$ using dashed lines. For $\sigma=0.06$ the initial response of inverse velocity is almost 100 basis points, which lies outside the VAR credible interval, while the unrestricted model captures the small short-run response of inverse velocity. After 20 periods, inverse velocity is about 10 basis points below its steady state level in the restricted model, which is still small but closer to the VAR credible interval. The long-run response (not shown in the figure) is about -50 basis points, whereas the $90 \%$ VAR credible interval ranges from -60 to -390 points. Thus, given the restrictions generated by the search-based DSGE models, we can either match the short-run or the long-run interest rate elasticity of money demand, but not both.

\section{Policy Analysis}

One of the advantages of having a structural model is the ability to conduct policy experiments. In our case, having a deeply founded money demand motive enables us to juxtapose the frictions that it brings against the (admittedly reduced-form) frictions that arise from the firms' problem. The particular policy experiment we consider is one where we change the long-run inflation target of the central bank, $\pi_{*}$ and assess its effect on welfare in a steady state in which the only sources of uncertainty are the realization of the Calvo shock on the firm side and households' opportunity to engage in a bilateral exchange in the DM. All aggregate shocks are set to zero and hence aggregate outcomes are non-stochastic. We hereby expect to capture the most important first-order effects. An extension of the welfare analysis to an environment with aggregate uncertainty is left for future research.

\subsection{Welfare Cost Channels}

There are five potential channels through which changes in the long-run inflation target can affect welfare in our model. First, inflation acts as a tax on money holdings and this reduces welfare. In our model, an increase in inflation increases the opportunity cost of holding money, reduces real money balances and reduces the equilibrium consumption in the DM, which will directly reduce welfare. In addition to this direct channel, since capital is used as an input to DM production, the return to holding capital falls due to the fall in DM consumption, leading to reduced investment in the CM. This will then reduce all real activity in the CM, including consumption, further reducing welfare. This channel is present in virtually all monetary 
models and it underlies Friedman's prescription of a zero percent net nominal interest rate, which has come to be known as the Friedman rule, as this eliminates the opportunity cost of holding money. We will label this effect of a change in the long-run inflation target on welfare the Friedman channel.

Unlike in cash-in-advance, MIU, or consumption transaction costs models, in our search-based environment the Friedman channel arises through the explicit modelling of bilateral exchanges. A traditional way to think about the opportunity cost of holding money is the welfare triangle (the area under the money demand curve), which was first discussed by Bailey (1956) and subsequently by Lucas (2000). It can be shown that in the absence of any other distortions, the welfare cost of inflation can be very well approximated by (in fact for some models exactly equal to) the area under the money demand curve between the two rates being compared. ${ }^{19}$ Therefore, the shape of the steady state relationship between inverse velocity and interest rate depicted in Figure 6 is key for determining the strength of the Friedman channel.

Second, our model has a nominal rigidity where some firms cannot optimally change their prices, which creates a relative price distortion. ${ }^{20}$ This distortion is captured by the deviation of $D_{t}$ in (35) from unity which would move the economy inside the production possibilities frontier by effectively destroying some of the outputs of the intermediate good firms. At the steady state, $D_{*}$ is given by

$$
D_{*}=\frac{(1-\zeta)\left[\frac{1}{1-\zeta}-\frac{\zeta}{1-\zeta}\left(\frac{1}{\pi_{*}}\right)^{-\frac{1-\iota}{\lambda}}\right]^{1+\lambda}}{1-\zeta\left(\frac{1}{\pi_{*}}\right)^{-\frac{(1+\lambda)(1-\iota)}{\lambda}}}
$$

which shows that for a given level of markup $\lambda$ and inflation, this distortion is affected by the fraction of firms that cannot adjust their price $(\zeta)$ and the fraction of the firms out of those that cannot adjust their price that can still dynamically index their price to lagged inflation $(\iota)$. In particular if either $\zeta=0$ or $\iota=1$, then $D_{*}=1$, which means this distortion is shut down. Moreover, holding the other parameter constant, an increase in $\zeta$ and a decrease in $\iota$ makes this distortion more severe. Finally, holding the parameters constant, the distortion becomes more severe as the steady state inflation rate moves away from $0 \%$ (in both directions), which in turn will reduce welfare. We will label this channel the relative-price distortion channel.

Third, monopolistic competition among intermediate good producers creates an additional distortion in our model. This distortion is captured by a positive markup in the CM, given by $\lambda$ and by moving the real wage rate away from the marginal product of labor, it can be thought of as creating a wedge similar to a labor income tax. To see this, shutting down the second channel above by setting $\zeta=0$, the intratemporal

\footnotetext{
${ }^{19}$ Craig and Rocheteau (2008) show that in the basic Lagos-Wright model, in the absence of any holdup problems, the area under the money demand curve very closely approximates the consumption-equivalent welfare measure we will also use. When holdup problems are present, the area under the money demand curve underestimates the welfare loss.

${ }^{20}$ See Wolman (2001) for a more in-depth discussion of this and the next channel.
} 
optimality condition becomes

$$
\frac{U^{\prime}\left(X_{*}\right)}{A}=\frac{1+\lambda}{(1-\alpha) Z_{*}\left(\frac{H_{*}}{K_{*}}\right)^{-\alpha}}
$$

where the left-hand side is the marginal rate of substitution between CM consumption and labor and $\lambda>0$ creates a wedge between this and the marginal rate of substitution. ${ }^{21}$ While it is not obvious from this equation, as Wolman (2001) shows, this distortion is minimized at a slightly positive inflation rate. We will label this channel the markup channel and will refer to this and the previous channel collectively as the New Keynesian channel. The price-taking version of our model will display only these three channels.

There are two more distortions in the bargaining version of our model which are explained in detail in AWW. To summarize, the bilateral nature of trade and the fact that the surplus in a meeting is split by the two parties in the DM create two holdup problems: the buyers do not bring in the optimal amount of money (a money demand holdup problem) and the sellers do not bring in the optimal amount of capital (an investment holdup problem). These holdup problems are aggravated as inflation increases, since this further reduces the payoffs in the DM by reducing $q$. We will collectively refer to these two sources of welfare loss as the holdup problem channel.

Our discussion so far makes it clear that the Friedman channel and the New Keynesian channel have different implications for welfare. The welfare loss of inflation from the Friedman channel is minimized (in fact eliminated) at the Friedman rule of zero percent net nominal interest rate (or an inflation target for the central bank equal to the minus the rate of time preference). On the other hand, the loss due to the New Keynesian channel is minimized around a zero percent inflation target. When both of these channels are present, the inflation rate that minimizes the overall distortions may be at either of the two extremes or somewhere in between.

The key parameters that control the strength of the New Keynesian channel are $\zeta$ and $\iota$. While the importance of $\zeta$ is well recognized in the literature, the sensitivity of welfare analysis to $\iota$ is less appreciated. $\zeta$ and $\iota$ control the shape of the New Keynesian Phillips curve and are identified from the output and inflation dynamics, where $\iota$ in particular adjusts to capture the inflation persistence. The strength of the Friedman channel is mostly determined by the DM participation probability $\sigma$, which is identified from the comovements of velocity and interest rates. As explained in the previous section, we will consider two sets of estimates. One obtained from the likelihood-based estimation of the search-based DSGE models, and the other one by matching the model's implied interest elasticity of money demand to estimates of long-run elasticities and re-estimating the rest of the parameters.

\footnotetext{
${ }^{21}$ It is common to use a labor income subsidy to offset the effect of the positive markup. As Schmitt-Grohe and Uribe (2007) also note, we find this arbitrary and refrain from doing so, especially given our objective of finding the net welfare effect of all the distortions in our model.
} 


\subsection{Welfare Calculations}

Before we turn to the results, a brief discussion about how we compute the welfare loss is in order. In our model, the reduced-form steady state welfare, or equivalently the social welfare function which places equal weights on all households, up to a constant is given by

$$
V\left(\pi_{*}\right)=\sigma\left[u\left(q_{*}\right)-c\left(q_{*}, k_{*}, Z_{*}\right)\right]+U\left(x_{*}\right)-A h_{*}
$$

We solve for the percentage change required in $x_{*}$ and consumption in the DM (the $q_{*}$ in $u\left(q_{*}\right)$ ) to make the households indifferent between two economies with different steady state inflation rates. We use an annual inflation rate of $2.5 \%$ as a benchmark, which is the average inflation rate at the end of our sample. Finally,

as a technical point, we replace $\left(1-\frac{1}{g_{*}}\right) \mathcal{Y}_{*}$ with simply a constant $G_{*}$ obtained from the estimations to prevent any welfare effects coming through this term.

Figure 7 plots the welfare cost of deviating from the benchmark target of $2.5 \%$ inflation for the four versions of the model we considered in the previous section using the posterior mean parameter estimates. The versions differ on whether the holdup problems are present (B) or not (PT) and whether $\sigma$ was estimated to capture the short-run interest elasticity of money demand (SR) or fixed to capture the long-run interest elasticity (LR). All versions show that some target in the interval between the Friedman rule and price stability leads to a lower welfare loss than the benchmark target, with a gain between $0.2 \%-0.6 \%$ of consumption. This is not surprising since all the channels we identified above agree that positive inflation is not desirable. While welfare costs are fairly steep to the right of $0 \%$, they are quite flat to the left of $0 \%$. For some versions, the welfare difference between the Friedman rule and price stability is less than $0.05 \%$. Thus, in this target inflation region the Friedman channel and the New Keynesian channel work in opposite directions and their strengths are similar. This finding contrasts with the MIU version of the New Keynesian model discussed in the previous section, where welfare loss is almost symmetric around $0 \%$ inflation.

As we compare the four DSGE model versions, we need to account for several simultaneous changes. First, as we replace bargaining by price-taking, the holdup problem channel disappears, which reduces the desirability of the Friedman rule. Accordingly the welfare gain of moving to the Friedman rule is lowered. Second, as we move from SR to LR versions two effects are present. As Figure 6 illustrates, the money demand curve becomes steeper, which increases the area underneath in the region to the left of $0 \%$ inflation. This rotation strengthens the Friedman channel. However, after the model is re-estimated, the estimates of $\zeta$ are only slightly lower, while the estimates of $\iota$ drop significantly. The reduced dynamic indexation strengthens the New Keynesian channel substantially. As a result, the welfare cost curve for the LR versions are lower (reflecting the increased Friedman channel) and more convex (reflecting the increased New Keynesian channel). 
To isolate the effects of the holdup channel and the slope of the money demand curve from that of the New Keynesian channel, Figure 8 plots welfare costs holding the New Keynesian channel fixed at $\zeta=0.81$ and $\iota=0.09$. Now it becomes clear that the Friedman channel is larger in the bargaining version than in the price-taking version, and it becomes stronger as one increases the interest elasticity of money demand. Therefore, returning to Figure 7, it seems that going from SR to LR, the New Keynesian channel increases in strength compared to the Friedman channel. We deduce that except for the bargaining (SR) version, which has a very sharp prediction about welfare, the welfare gains of reducing the target inflation rate below $0 \%$ are fairly insensitive to the actual value that is chosen.

\subsection{Accounting for Uncertainty}

The central question we want to address is finding the optimal inflation target for the central bank in the presence of all (or some) of the five channels we discussed above. From Figure 7 we can see that for the bargaining version (SR), the Friedman rule is the optimal policy, which means that the Friedman channel, the desire to avoid the opportunity cost of holding money, together with the holdup problem channel is significantly bigger than the New Keynesian channel. In other versions of the model, the optimal inflation appears to be between the Friedman rule and price stability, but never very close to price stability.

The evidence from the analysis thus far and other related studies makes it clear that the answer to this question crucially depends on the parameter choices, especially $\zeta, \iota$, and $\sigma$. Our Bayesian framework is perfectly suited to account for parameter (and model) uncertainty. A casual inspection of Table 2 indicates that the degree of indexation $\iota$ is the least precisely estimated among the three key parameters and this large uncertainty about $\iota$ is likely to translate into substantial uncertainty with respect to policy effects.

While we could convert the marginal data densities reported in Table 5 into posterior model probabilities and average across models, we decided in view of the overall model misspecification concerns to report results for each version separately. For each draw $\vartheta$ from the posterior distribution of a particular DSGE model specification we can compute the $\pi_{*}$ that yields the largest welfare gain, which we denote as $\pi_{*}^{o p t}(\vartheta)$. Now suppose we consider a particular target inflation rate $\bar{\pi}_{*}$. For each draw $\vartheta$, we can calculate a "regret," that is, the differential between the welfare gains attained with $\pi_{*}^{o p t}(\vartheta)$ and $\bar{\pi}_{*}$, respectively. Figure 9 depicts the posterior probability that this regret is less than $0.01 \%$ as a function of $\bar{\pi}_{*}$.

Our results indicate that by and large the welfare differences among inflation targets between 0 and $-2.5 \%$ is fairly small. For example, if we consider a posterior probability of 0.5 as a threshold, the lowregret inflation targets range from $-2 \%$ and $-1 \%(\mathrm{SBM}(\mathrm{B}-\mathrm{LR})$ ), Friedman rule and $-1 \%$ (SBM(PT-SR)), and $-1.25 \%$ and $-0.3 \%$ (SBM(PT-LR)), respectively. Thus, even the $\operatorname{SBM}(\mathrm{PT}-\mathrm{LR})$, which has a strong New Keynesian channel and no holdup problem channel, does not rule out inflation targets less than $-1 \%$. 
The only specification that yields fairly sharp policy prescriptions is SBM(B-SR). It strongly favors inflation rates that are very close to the Friedman rule with rates above $-2 \%$ receiving a posterior probability of less than 0.05. We want to emphasize that this specification attains the highest marginal likelihood among the four versions of the model we consider. This means that if we were to use the model weights implied by the marginal log-likelihoods, this version would get virtually all the weight.

To summarize, a target inflation rate of $-1 \%$, which is substantially lower than the $2 \%$ rate favored by most inflation targeting countries, leads to a lower welfare cost in terms of our social welfare function in all of the search-based models we considered. Someone who is willing to rely on the estimated posterior model weights, might want to lower that target inflation rate even further to realize all potential welfare gains. Our analysis has one important caveat. We do not account for aggregate uncertainty. Since the Friedman channel favors near-zero nominal interest rates, the stochastic analysis requires a careful treatment of the zero lower bound. We will leave such an analysis for future work.

\section{Conclusion}

As an alternative to the commonly used cashless New Keynesian model, or its "cash-filled" MIU counterpart, we have developed an estimable DSGE model in which the presence of a decentralized market creates an incentive for households to hold money and money's role as a medium of exchange emerges endogenously. The model specification is closely tied to the theoretical literature that is developing micro-founded models of monetary exchange, in particular Lagos and Wright (2005), and Aruoba, Waller, and Wright (2008). We

discipline our model by making fairly standard choices about utility and production functions defined over consumption goods, instead of choosing arguably arbitrary functional forms for the utility derived from real money balances or the cost of transactions.

Using postwar U.S. data on output, inflation, interest rates, and (inverse) velocity, we estimate several versions of our search-based DSGE model. Most important, we obtain estimates for the parameters that determine the exchange in the decentralized market and the price rigidity in the centralized market. Thus, the econometric analysis provides us with a measurement of the relative strength of the various channels through which target inflation rates affect welfare. We explore the steady state welfare implications of our model, taking parameter uncertainty into account. Our findings suggest that the regret of a central bank (of not choosing the policy that is optimal under the "true" parameters) is fairly small in the region of $[-2.5 \%, 0 \%]$ inflation. Moreover, considering uncertainty about the pricing mechanism in the DM, which has implications about the presence of holdup problems, and whether to match the short- or long-run interest elasticity of money demand, we find that negative inflation targets, especially those less than $-1 \%$ maximize 
the social welfare function we consider. Thus, the standard prescription of a cashless New Keynesian model, $0 \%$ long-run inflation, leads to a lower welfare according to our model.

A caveat remains. Our quantitative result is certainly at odds with the general practice in central banks around the world. We know of no central bank that either explicitly or implicitly follows a deflationary policy in the longrun. This suggests that the motives behind non-negative inflation targets of central banks are not explicit in our model or in many related models. Billi and Kahn (2008) list a number of reasons why a low but positive level of inflation may be useful. Among these are measurement errors - that observed inflation may not be an accurate assessment of actual inflation - the effect of deflation on debts, and downward nominal wage rigidity, none of which is present in our model. Finally, an aspect of monetary policy that we have not addressed is optimal short-run stabilization in the presence of a lower bound on nominal interest rates. Another reason why central banks may prefer a positive long-run inflation target is that otherwise aggregate

shocks may push the economy too close to the zero bound. We leave a formal analysis of stabilization policies to future work.

\section{References}

An, Sungbae (2007): "Bayesian Estimation of DSGE Models: Lessons from Second-Order Approximations," Manuscript, Singapore Management University.

An, Sungbae and Frank Schorfheide (2007): "Bayesian Analysis of DSGE Models," Econometric Reviews, 26(2-4), 113-172.

Andres, Javier, Lopez-Salido, J. David and Edward Nelson (2004): “Tobin's Imperfect Asset Substitution in Optimizing General Equilibrium," Journal of Money, Credit and Banking, 36, 665-690.

Andres, Javier, Lopez-Salido, J. David and Edward Nelson (2007): "Sticky-price Models and the Natural Rate Hypothesis," Journal of Monetary Economics, 52, 1025-1053.

Aruoba, S. Borağan and Sanjay K. Chugh (2007): "Optimal Fiscal and Monetary Policy When Money Is Essential," Manuscript, University of Maryland.

Aruoba, S. Borağan and Sanjay K. Chugh (2008): "Money and Optimal Capital Taxation," Manuscript, University of Maryland.

Aruoba, S. Borağan, Guillaume Rocheteau and Christopher Waller (2007): "Bargaining and the Value of Money," Journal of Monetary Economics, 54, 2636-2655. 
Aruoba, S. Borağan, Christopher Waller, and Randall Wright (2008): "Money and Capital : A Quantitative Analysis," Manuscript, University of Maryland.

Ascari, Guido and Tiziano Ropele (2007): "Optimal Monetary Policy under Low Trend Inflation," Journal of Monetary Economics, 54, 2568-2583.

Bailey, Martin (1956): "The Welfare Cost of Inflationary Finance," Journal of Political Economy, 64, 93-110.

Ball, Lawrence (2001): "Another Look at Long-Run Money Demand," Journal of Monetary Economics, 47, 31-44.

Berentsen, Aleksander, Gabriele Camera and Christopher Waller (2007): "Money, Credit and Banking," Journal of Economic Theory, 135, 171-195.

Billi, Roberto (2008): "Optimal Inflation for the U.S. Economy," Federal Reserve Bank of Kansas City Research Working Papers, RWP 07-03.

Billi, Roberto and George Kahn (2008): "What Is the Optimal Inflation Rate?, Federal Reserve Bank of Kansas City Economic Review, 5-28.

Bouakez, Hafedh, Cardia, Emanuela, and Fransisco J. Ruge-Murcia (2005): "Habit Formation and the Persistence of Monetary Shocks," Journal of Monetary Economics, 52, 1073-1088.

Bouakez, Hafedh, Cardia, Emanuela, and Fransisco J. Ruge-Murcia (2009): "The Transmission of Monetary Policy in a Multi-sector Economy," International Economic Review, forthcoming.

Calvo, Guillermo (1983): "Staggered Prices in a Utility-Maximizing Framework," Journal of Monetary Economics, 12, 383-398.

Christinsen, Ian and Ali Dib (2008): "The Financial Accelerator in an Estimated New Keynesian Model," Review of Economic Dynamics, 11, 155-178.

Christiano, Lawrence, Martin Eichenbaum, and Charles Evans (2005): "Nominal Rigidities and the Dynamic Effects of a Shock to Monetary Policy," Journal of Political Economy, 113, 1-45.

Craig, Ben and Guillaume Rocheteau (2008): "Inflation and Welfare: A Search Approach," Journal of Money, Credit, and Banking, 40, 89-120.

Cynamon, Barry, Donald Dutkowsky, and Barry Jones (2006): "Redefining the Monetary Aggregates: A Clean Sweep," Eastern Economic Journal, 32, 661-672. 
Del Negro, Marco and Frank Schorfheide (2008): "Forming Priors for DSGE Models (and How it Affects the Assessment of Nominal Rigidities)," Journal of Monetary Economics, 55, 1191-1208.

Doan, Thomas, Robert Litterman, and Christopher A. Sims (1984): "Forecasting and Conditional Projection Using Realistic Prior Distributions," Econometric Reviews, 3, 1-100.

Geweke, John (1978): "The Revision of Seasonally Adjusted Time Series," Proceedings of the Business and Economic Statistics Section, American Statistical Association, 320-325.

Goldfeld, S. and D. Sichel (1990), "The Demand for Money," in B. Friedman and F. Hahn (eds.) The Handbook of Monetary Economics, 1, 299-356.

Goodfriend, Marvin and Robert King (1997): "The New Neoclassical Synthesis and the Role of Monetary Policy," NBER Macroeconomics Annual, 12, 231-283.

Guerron-Quintana, Pablo A. (2008): "The Implications of Inflation in an Estimated New-Keynesian Model," Manuscript, North Carolina State University.

Guerron-Quintana, Pablo A. (2009): "Money Demand Heterogeneity and the Great Moderation," Journal of Monetary Economics, 56, 255-266.

Hansen, Gary (1985): "Indivisible Labor and the Business Cycle," Journal of Monetary Economics, 16, 309-327.

Ireland, Peter (2004): "Money's Role in the Monetary Business Cycle," Journal of Money, Credit, and Banking, 36, 969-983.

Justiniano, Alejandro and Giorgio E. Primiceri (2008): "The Time Varying Volatility of Macroeconomic Fluctuations," American Economic Review, 98, 604-641.

Khan, Aubhik, Robert King and Alexander Wolman (2003), "Optimal Monetary Policy," Review of Economic Studies, 70, 825-860.

King, Robert, and Alexander Wolman (1996): "Inflation Targeting in a St. Louis Model of the 21st Century," FRB St. Louis Review, May-June.

Kiyotaki, Nobuhiro and Randall Wright (1989): "On Money as a Medium of Exchange," Journal of Political Economy, 97, 927-954.

Lagos, Ricardo and Randall Wright (2005): "A Unified Framework for Monetary Theory and Policy Evaluation," Journal of Political Economy, 113, 463-484. 
Levin, Andrew, Alexei Onatski, John Williams, and Noah Williams (2006): "Monetary Policy Under Uncertainty in Micro-Founded Macroeconometric Models" in Mark Gertler and Kenneth Rogoff (eds.) NBER Macroeconomics Annual 2005, MIT Press, Cambridge, MA.

Lubik, Thomas and Frank Schorfheide (2006): "A Bayesian Look at New Open Economy Macroeconomics," NBER Macroeconomics Annual 2005, 313-366.

Lucas, Robert (1988): "Money Demand in the United States: A Quantitative Review," Carnegie-Rochester Conference Series on Public Policy, 29, 137-167.

Lucas, Robert (2000): "Inflation and Welfare," Econometrica, 68, 247-274.

Pierce, D. (1980): "Data Revisions with Moving Average Seasonal Adjustment Procedures," Journal of Econometrics, 14, 95-114.

Primiceri, Giorgio (2006): "Why Inflation Rose and Fell: Policymakers Beliefs and US Postwar Stabilization Policy," Quarterly Journal of Economics, 121, 867-901.

Rabanal, Pau and Juan F. Rubio-Ramirez (2005): "Comparing New Keynesian Models of the Business Cycle: A Bayesian Approach," Journal of Monetary Economics, 52, 1151-1166.

Rocheteau, Guillaume, Peter Rupert, and Randall Wright (2008a): "Inflation and Unemployment in General Equilibrium," Scandinavian Journal of Economics, 109, 837-855.

Rocheteau, Guillaume, Peter Rupert, Karl Shell and Randall Wright (2008b): "General Equilibrium with Nonconvexities and Money," Journal of Economic Theory, 142, 294-317.

Rocheteau, Guillaume and Randall Wright (2005): "Money in Search Equilibrium, in Competitive Equilibrium, and in Competitive Search Equilibrium," Econometrica, 73, 175-202.

Rogerson, Richard (1988): "Indivisible Labor, Lotteries and Equilibrium," Journal of Monetary Economics, 66, 3-16.

Sargent, Thomas (1999): The Conquest of American Inflation, Princeton University Press.

Sargent, Thomas, Noah Williams and Tao Zha (2006): "Shocks and Government Beliefs: The Rise and Fall of American Inflation," American Economic Review, 96, 1193-1224.

Schmitt-Grohe, Stephanie, and Martin Uribe (2007): "Optimal Inflation Stabilization in a Medium-Scale Macroeconomic Model," in Monetary Policy Under Inflation Targeting, Klaus Schmidt-Hebbel and Frederic Mishkin (eds.), Central Bank of Chile, Santiago, Chile, p. 125-186. 
Schorfheide, Frank (2000): "Loss Function Based Evaluation of DSGE Models," Journal of Applied Econometrics, 15, 645-670.

Schorfheide, Frank (2005): "Learning and Monetary Policy Shifts," Review of Economic Dynamics, 8, 392-419.

Schorfheide, Frank (2009): "DSGE Model-Based Estimation of the New Keynesian Phillips Curve," Federal Reserve Bank of Richmond Economic Quarterly, forthcoming.

Sims, Christopher and Tao Zha (1998): "Bayesian Methods for Dynamic Multivariate Models," International Economic Review, 39, 949-968.

Smets, Frank and Raf Wouters (2003): "An Estimated Stochastic Dynamic General Equilibrium Model for the Euro Area," Journal of the European Economic Association, 1, 1123-1175.

Smets, Frank and Raf Wouters (2007): "Shocks and Frictions in US Business Cycles: A Bayesian DSGE Approach," American Economic Review, 97, 586-606.

Stock, James and Mark Watson (1993): "A Simple Estimator of Cointegrating Vectors in Higher Order Integrated Systems," Econometrica, 61, 783-820.

Waller, Christopher (2009): "Random Matching and Money in the Neoclassical Growth Model: Some Analytical Results," Manuscript.

Wolman, Alexander (2001): "A Primer on Optimal Monetary Policy with Staggered Price Setting," FRB Richmond Quarterly Review, 87-4, 27-52.

Woodford, Michael (2003): Interest and Prices, Princeton University Press, Princeton. 
Figure 1: Inflation, Target Inflation, M1-Velocity and Interest Rates
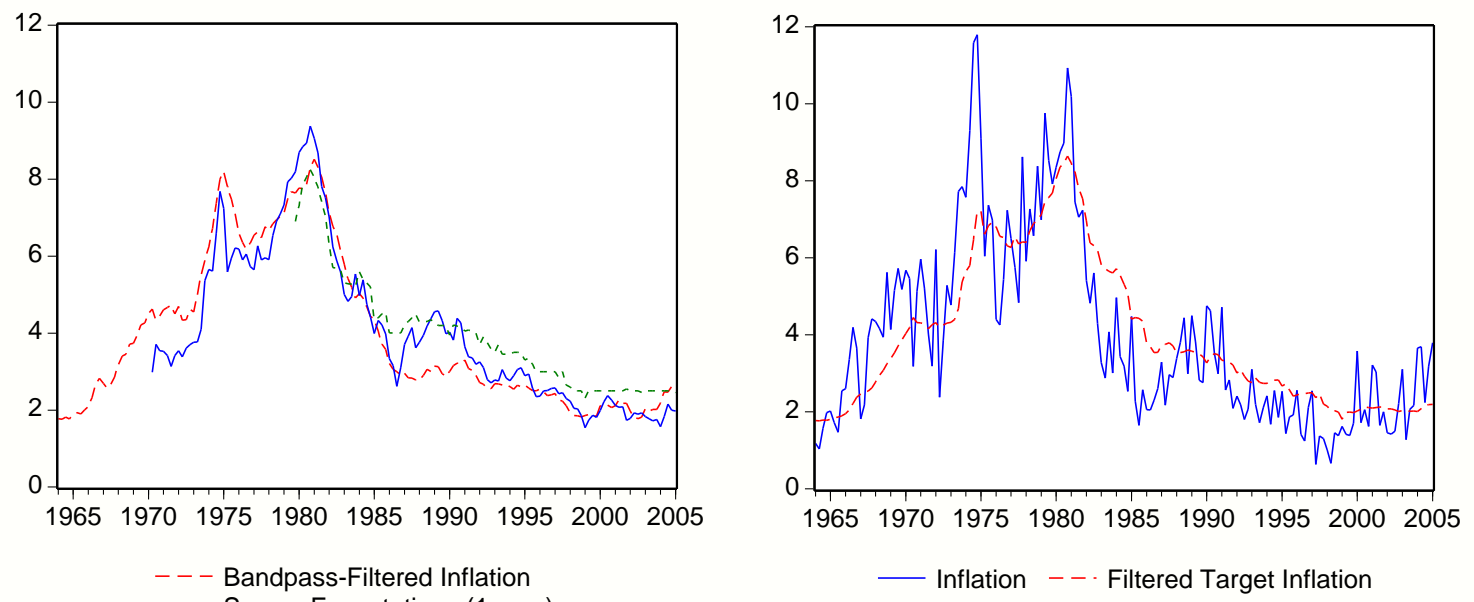

--- Bandpass-Filtered Inflation
- Survey Expectations (1 year)

- - - Survey Expectations (10 years)

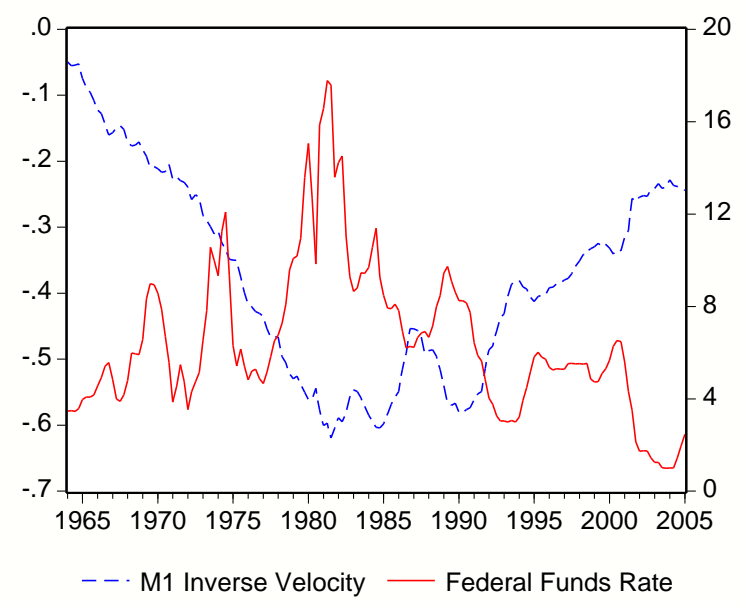


Table 1: Parameters Fixed During Estimation

\begin{tabular}{lr}
\hline \hline Preference Parameter $\chi_{*}$ & 1.00 \\
Preference Parameter $\kappa$ & $1 \mathrm{E}-4$ \\
Depreciation Rate $\delta$ & .014 \\
Fixed Costs $\mathcal{F}$ & 0.00 \\
Indexation $\pi_{* *}$ & 1.00 \\
Steady State GDP $\mathcal{Y}_{*}$ & 1.00 \\
Steady State $\ln \left(H_{*} / Y_{*}\right)$ & -3.35 \\
Steady State Inv Velocity $\ln \left(\mathcal{M}_{*} / \mathcal{Y}_{*}\right)$ & -0.38 \\
Share of Government Spending $g_{*}$ & 1.20 \\
Steady State Real Rate $r_{A}$ & 2.50 \\
Central Bank's Reaction to Inflation $\psi_{1}$ & 1.70 \\
\hline
\end{tabular}

Notes: We use the following transformations: $\beta=1 /\left(1+r_{A} / 400\right), \pi_{*}=1+\pi_{A} / 400$. The model is loglinearized around $\pi_{A}=4.00$. 
Table 2: Prior and Posterior Distributions

\begin{tabular}{|c|c|c|c|c|c|c|c|c|}
\hline \multirow[b]{3}{*}{ Name } & \multirow[b]{3}{*}{ Domain } & \multicolumn{3}{|c|}{ Prior Distributions } & \multicolumn{4}{|c|}{ Posterior Distributions } \\
\hline & & \multirow[b]{2}{*}{ Density } & \multirow[b]{2}{*}{ Para (1) } & \multirow[b]{2}{*}{ Para (2) } & \multicolumn{2}{|c|}{$\operatorname{SBM}(B)$} & \multicolumn{2}{|c|}{$\mathrm{SBM}(\mathrm{PT})$} \\
\hline & & & & & Mean & $90 \%$ Intv & Mean & $90 \%$ Intv \\
\hline \multicolumn{9}{|c|}{ Households } \\
\hline$\theta$ & {$[0,1)$} & Uniform & 0.00 & 1.00 & 0.95 & {$[0.95,0.96]$} & & \\
\hline $2 \sigma$ & {$[0,1)$} & Beta & 0.40 & 0.20 & 0.63 & {$[0.56,0.70]$} & 0.59 & {$[0.52,0.66]$} \\
\hline \multicolumn{9}{|c|}{ Firms } \\
\hline$\alpha$ & {$[0,1)$} & Beta & 0.30 & .025 & 0.32 & {$[0.31,0.34]$} & 0.27 & {$[0.26,0.28]$} \\
\hline$\lambda$ & $\mathbb{R}^{+}$ & Gamma & 0.15 & 0.05 & 0.14 & {$[0.12,0.16]$} & 0.19 & {$[0.18,0.21]$} \\
\hline$\zeta$ & {$[0,1)$} & Beta & 0.60 & 0.15 & 0.83 & {$[0.79,0.87]$} & 0.84 & {$[0.80,0.88]$} \\
\hline$\iota$ & {$[0,1)$} & Beta & 0.50 & 0.25 & 0.72 & {$[0.54,0.91]$} & 0.57 & {$[0.31,0.82]$} \\
\hline$S^{\prime \prime}$ & $\mathbb{R}^{+}$ & Gamma & 5.00 & 2.50 & 4.89 & {$[2.50,7.36]$} & 5.08 & {$[2.42,7.71]$} \\
\hline \multicolumn{9}{|c|}{ Central Bank } \\
\hline$\psi_{2}$ & $\mathbb{I R}^{+}$ & Gamma & 0.20 & 0.10 & 0.86 & {$[0.64,1.06]$} & 0.83 & {$[0.64,1.02]$} \\
\hline$\rho_{R}$ & {$[0,1)$} & Beta & 0.50 & 0.20 & 0.61 & {$[0.56,0.66]$} & 0.60 & {$[0.55,0.65]$} \\
\hline$\sigma_{R}$ & $\mathbb{R}^{+}$ & InvGamma & 0.50 & 4.00 & 0.36 & {$[0.31,0.41]$} & 0.37 & {$[0.31,0.42]$} \\
\hline$\sigma_{R, 2}$ & $\mathbb{R}^{+}$ & InvGamma & 1.00 & 4.00 & 0.85 & {$[0.63,1.07]$} & 0.85 & {$[0.62,1.08]$} \\
\hline$\tilde{\pi}_{A, 0}^{*}$ & $\mathbb{R}$ & Normal & 0.00 & 2.00 & 0.05 & {$[-3.21,3.26]$} & 0.02 & {$[-3.22,3.28]$} \\
\hline$\sigma_{\pi}$ & $\mathbb{R}^{+}$ & InvGamma & 0.05 & 4.00 & 0.05 & {$[0.04,0.05]$} & 0.05 & {$[0.04,0.05]$} \\
\hline \multicolumn{9}{|c|}{ Shocks } \\
\hline$\rho_{g}$ & {$[0,1)$} & Beta & 0.80 & 0.10 & 0.84 & {$[0.81,0.88]$} & 0.87 & {$[0.83,0.90]$} \\
\hline$\sigma_{g}$ & $\mathbb{R}^{+}$ & InvGamma & 1.00 & 4.00 & 1.01 & {$[0.90,1.11]$} & 1.06 & {$[0.94,1.16]$} \\
\hline$\rho_{\chi}$ & {$[0,1)$} & Beta & 0.80 & 0.10 & 0.97 & {$[0.97,0.98]$} & 0.96 & {$[0.95,0.97]$} \\
\hline$\sigma_{\chi}$ & $\mathbb{R}^{+}$ & InvGamma & 1.00 & 4.00 & 1.80 & {$[1.63,1.97]$} & 1.88 & {$[1.70,2.05]$} \\
\hline$\rho_{Z}$ & {$[0,1)$} & Beta & 0.80 & 0.10 & 0.83 & {$[0.76,0.90]$} & 0.83 & {$[0.77,0.89]$} \\
\hline$\sigma_{Z}$ & $\mathbb{R}^{+}$ & InvGamma & 1.00 & 4.00 & 1.04 & {$[0.90,1.17]$} & 1.06 & {$[0.91,1.21]$} \\
\hline
\end{tabular}

Notes: Para (1) and Para (2) list the means and the standard deviations for Beta, Gamma, and Normal distributions; the upper and lower bound of the support for the Uniform distribution; $s$ and $\nu$ for the Inverse Gamma distribution, where $p_{\mathcal{I G}}(\sigma \mid \nu, s) \propto \sigma^{-\nu-1} e^{-\nu s^{2} / 2 \sigma^{2}}$. 
Table 3: Posterior Steady States

\begin{tabular}{lcccc}
\hline \hline & \multicolumn{2}{c}{$\mathrm{SBM}(\mathrm{B})$} & \multicolumn{2}{c}{$\mathrm{SBM}(\mathrm{PT})$} \\
& Mean & $90 \%$ Intv & Mean & $90 \%$ Intv \\
\hline$A$ & 16.1 & {$[15.5,16.7]$} & 24.3 & {$[23.8,24.8]$} \\
$B$ & 0.44 & {$[0.41,0.46]$} & 0.65 & {$[0.62,0.68]$} \\
$Z_{*}$ & 4.10 & {$[3.70,4.47]$} & 5.48 & {$[5.05,5.89]$} \\
\hline$I_{*} / \mathcal{Y}_{*}$ & 0.16 & {$[0.15,0.16]$} & 0.16 & {$[0.16,0.17]$} \\
$K_{*} / \mathcal{Y}_{*}$ & 11.1 & {$[10.6,11.6]$} & 11.8 & {$[11.3,12.3]$} \\
$W_{*} H_{*} / Y_{*}$ & 0.60 & {$[0.58,0.61]$} & 0.61 & {$[0.60,0.62]$} \\
Overall Markup & 0.14 & {$[0.13,0.16]$} & 0.16 & {$[0.14,0.17]$} \\
\hline DM Share & 0.21 & {$[0.19,0.24]$} & 0.20 & {$[0.18,0.22]$} \\
DM Markup & 0.17 & {$[0.11,0.24]$} & & 0.000 \\
\hline
\end{tabular}

Notes: Aggregate output is normalized to $\mathcal{Y}_{*}=1$ in the two versions of the search-based DSGE model. 
Table 4: Posterior Variance Decomposition (Business Cycle Freq)

\begin{tabular}{|c|c|c|c|c|}
\hline \multirow[t]{2}{*}{ Shock } & \multicolumn{2}{|c|}{$\operatorname{SBM}(B)$} & \multicolumn{2}{|c|}{$\mathrm{SBM}(\mathrm{PT})$} \\
\hline & Mean & $90 \%$ Intv & Mean & $90 \%$ Intv \\
\hline \multicolumn{5}{|c|}{ Output } \\
\hline Gov Spending & 0.51 & {$[0.43,0.61]$} & 0.53 & {$[0.42,0.60]$} \\
\hline Money Demand & 0.05 & {$[0.03,0.07]$} & 0.06 & {$[0.03,0.09]$} \\
\hline Monetary Policy & 0.12 & {$[0.07,0.17]$} & 0.12 & {$[0.06,0.18]$} \\
\hline Technology & 0.32 & {$[0.23,0.40]$} & 0.29 & {$[0.21,0.38]$} \\
\hline Target Inflation & 0.01 & {$[0.00,0.01]$} & 0.01 & {$[0.00,0.01]$} \\
\hline \multicolumn{5}{|c|}{ Inflation } \\
\hline Gov Spending & 0.18 & {$[0.14,0.23]$} & 0.17 & {$[0.13,0.21]$} \\
\hline Money Demand & 0.01 & {$[0.00,0.01]$} & 0.01 & {$[0.00,0.02]$} \\
\hline Monetary Policy & 0.23 & {$[0.17,0.28]$} & 0.21 & {$[0.15,0.25]$} \\
\hline Technology & 0.50 & {$[0.45,0.58]$} & 0.51 & {$[0.45,0.58]$} \\
\hline Target Inflation & 0.08 & {$[0.05,0.12]$} & 0.10 & {$[0.06,0.13]$} \\
\hline \multicolumn{5}{|c|}{ Inverse Velocity } \\
\hline Gov Spending & 0.44 & {$[0.38,0.49]$} & 0.46 & {$[0.40,0.52]$} \\
\hline Money Demand & 0.52 & {$[0.46,0.57]$} & 0.50 & {$[0.44,0.55]$} \\
\hline Monetary Policy & 0.02 & {$[0.02,0.03]$} & 0.03 & {$[0.02,0.03]$} \\
\hline Technology & 0.02 & {$[0.01,0.03]$} & 0.01 & {$[0.00,0.02]$} \\
\hline Target Inflation & 0.00 & {$[0.00,0.00]$} & 0.00 & {$[0.00,0.00]$} \\
\hline \multicolumn{5}{|c|}{ Real Money Balances } \\
\hline Gov Spending & 0.11 & {$[0.07,0.14]$} & 0.12 & {$[0.08,0.16]$} \\
\hline Money Demand & 0.70 & {$[0.65,0.74]$} & 0.69 & {$[0.63,0.73]$} \\
\hline Monetary Policy & 0.13 & {$[0.09,0.17]$} & 0.13 & {$[0.09,0.16]$} \\
\hline Technology & 0.07 & {$[0.05,0.11]$} & 0.06 & {$[0.03,0.10]$} \\
\hline Target Inflation & 0.00 & {$[0.00,0.00]$} & 0.00 & {$[0.00,0.00]$} \\
\hline
\end{tabular}

Notes: Real money balances are measured in terms of the CM good. 
Figure 2: Impulse Responses to Technology Shock
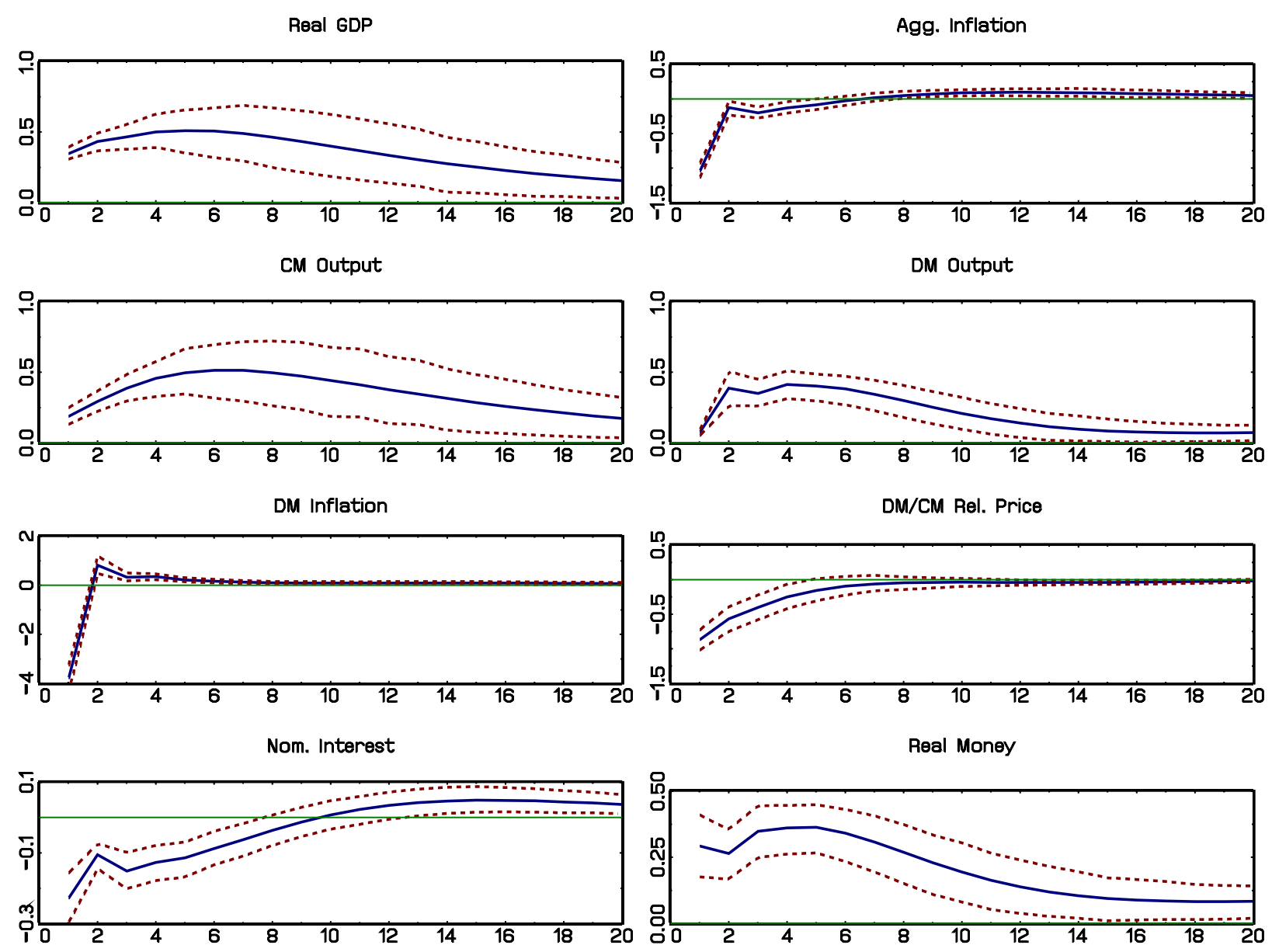

Notes: Figure depicts pointwise posterior mean and 90\% credible interval of impulse responses for $\operatorname{SBM}(\mathrm{B})$ model. Responses of inflation and fed funds rate are measured in percentage points and responses of real output, real money balances, and relative prices are measured in percentage deviations from the steady state. 
Real GDP
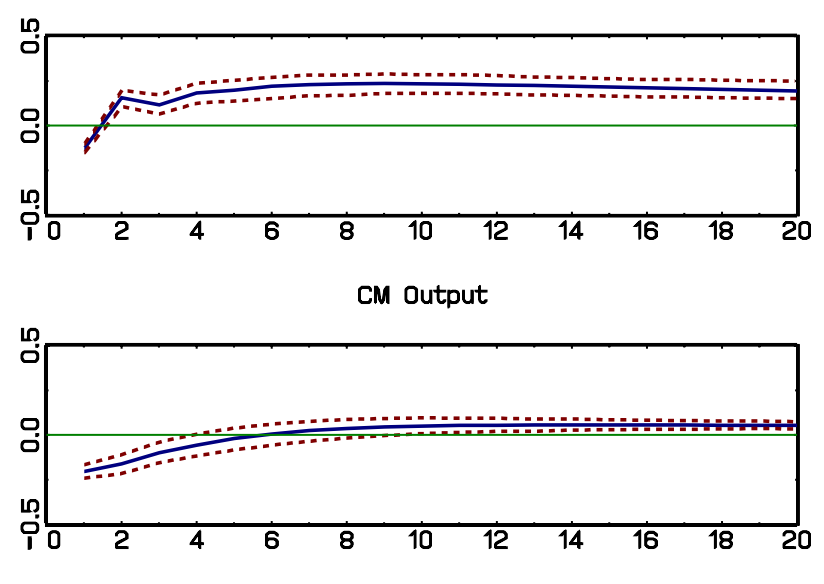

DM Inflation
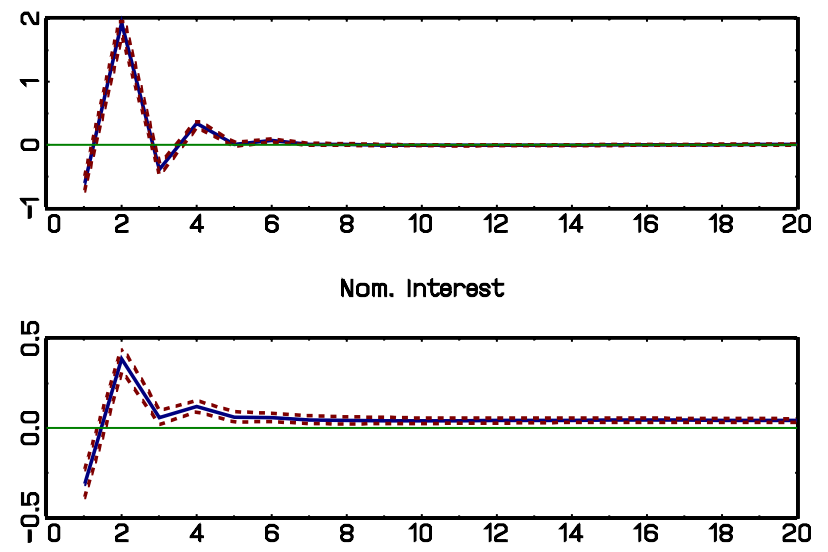

Agg. Inflation

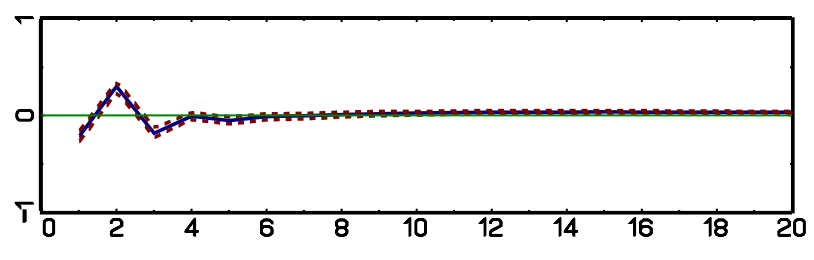

DM Output

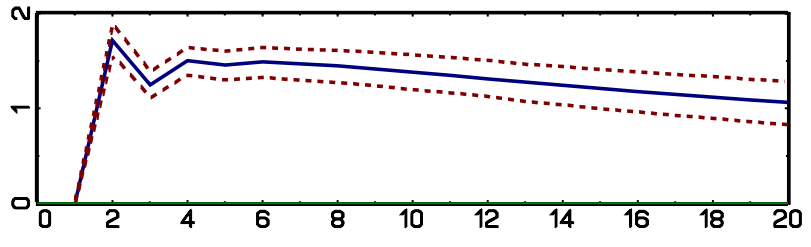

DM/CM Rel. Price
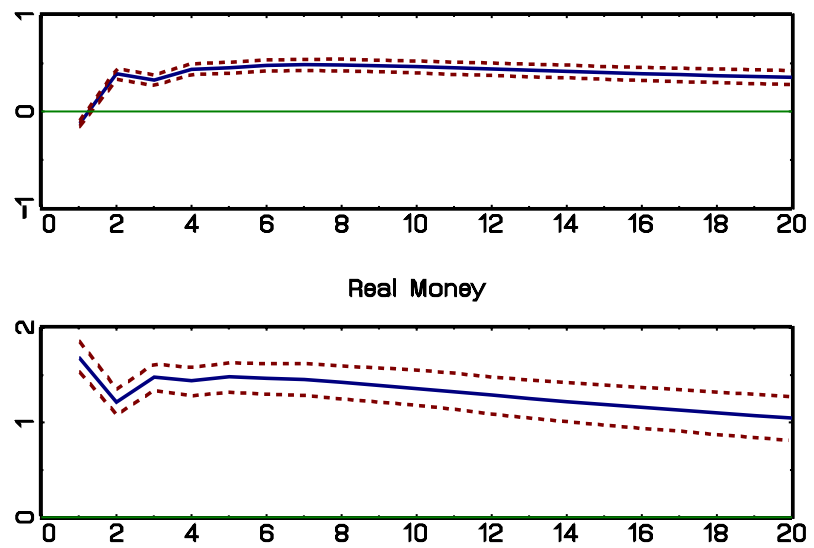

Notes: Figure depicts pointwise posterior mean and 90\% credible interval of impulse responses for SBM(B) model. Responses of inflation and fed funds rate are measured in percentage points and responses of real output, real money balances, and relative prices are measured in percentage deviations from the steady state. 
Figure 4: Impulse Responses to Monetary Policy $\left(\epsilon_{R, t}\right)$ Shock
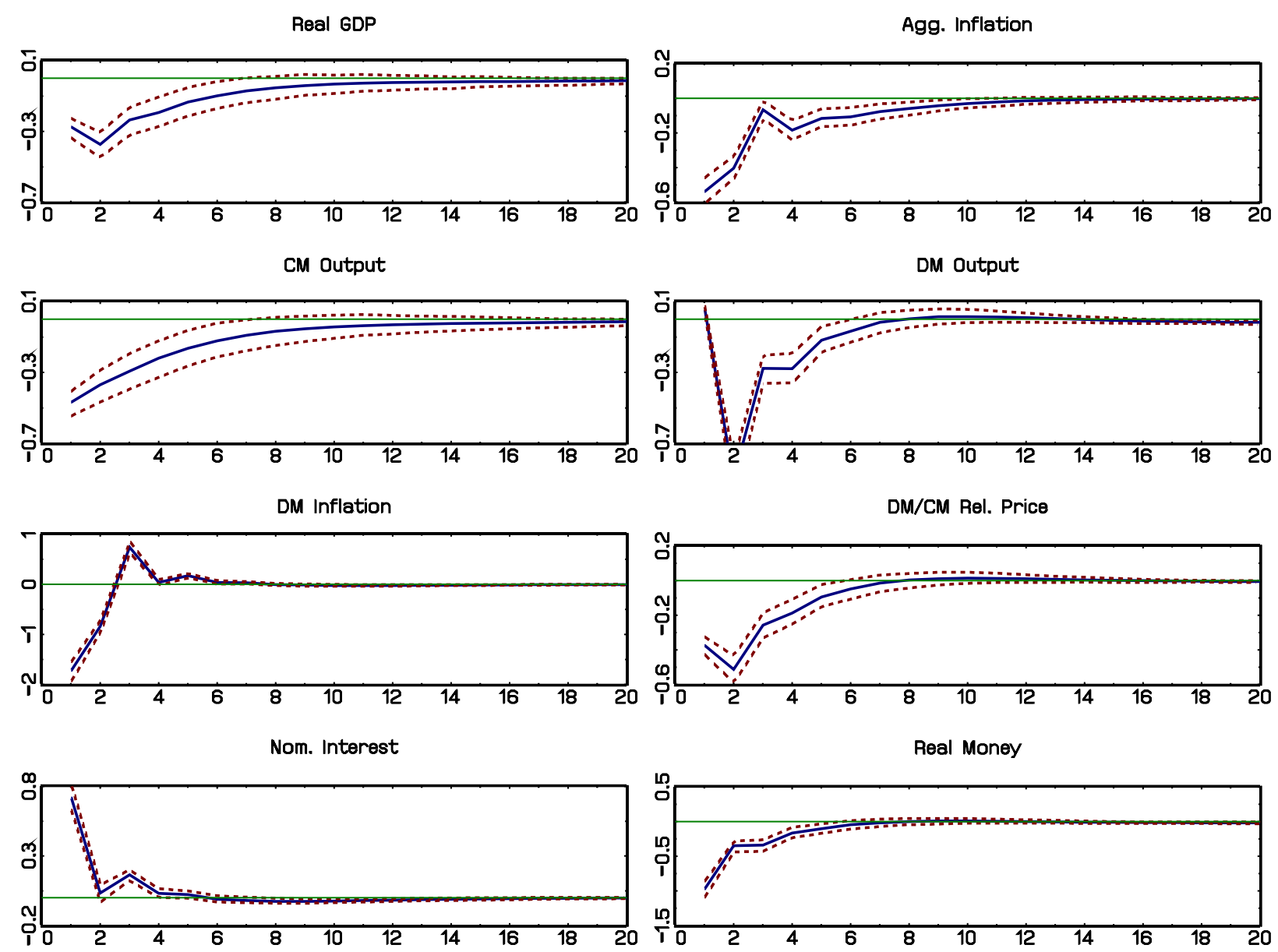

Notes: Figure depicts pointwise posterior mean and 90\% credible interval of impulse responses for $\operatorname{SBM}(\mathrm{B})$ model. Responses of inflation and fed funds rate are measured in percentage points and responses of real output, real money balances, and relative prices are measured in percentage deviations from the steady state. 
Table 5: Marginal Data Densities and RMSEs

\begin{tabular}{|c|c|c|c|c|c|c|}
\hline \multirow[b]{2}{*}{ Model } & & \multirow[b]{2}{*}{$\ln p\left(Y^{T}\right)$} & \multicolumn{4}{|c|}{ In-Sample RMSE } \\
\hline & & & Output & Inflation & Interest & Inv. Velocity \\
\hline $\operatorname{SBM}(B)$ & & -998.43 & 0.81 & 1.18 & 1.41 & 2.17 \\
\hline $\mathrm{SBM}(\mathrm{PT})$ & & $-1,007.26$ & 0.83 & 1.18 & 1.42 & 2.32 \\
\hline MIU & & -949.14 & 0.86 & 1.08 & 1.06 & 1.43 \\
\hline $\operatorname{VAR}(4)$ & & -924.14 & 0.85 & 0.96 & 0.87 & 1.31 \\
\hline $\operatorname{SBM}(B)$ & $\sigma=0.06$ & $-1,126.00$ & 0.83 & 1.08 & 1.15 & 3.22 \\
\hline $\mathrm{SBM}(\mathrm{PT})$ & $\sigma=0.06$ & $-1,126.59$ & 0.83 & 1.08 & 1.15 & 3.20 \\
\hline MIU & $\nu=5.15$ & $-1,092.52$ & 0.86 & 1.09 & 1.07 & 2.39 \\
\hline
\end{tabular}

Notes: The marginal data densities for all models are computed conditional on the four observations 1964:I to 1964:IV that are used to initialize the lags of the VAR. The RMSEs are computed at the posterior mode and measured as follows: output is in percentage deviations from the linear trend, inverse velocity is in percentage deviations from the sample mean, inflation and interest rates are in annualized percentages. 
Figure 5: Impulse Responses to Inflation Target $\left(\epsilon_{\pi, t}\right)$ Shock

Real GDP

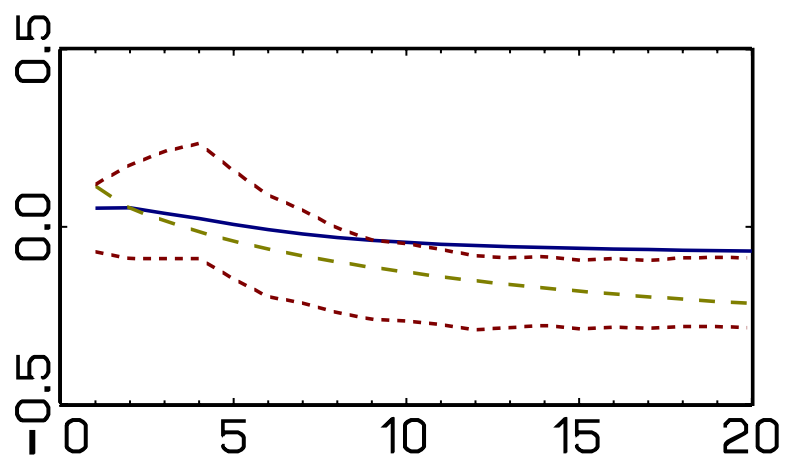

Nom. Interest

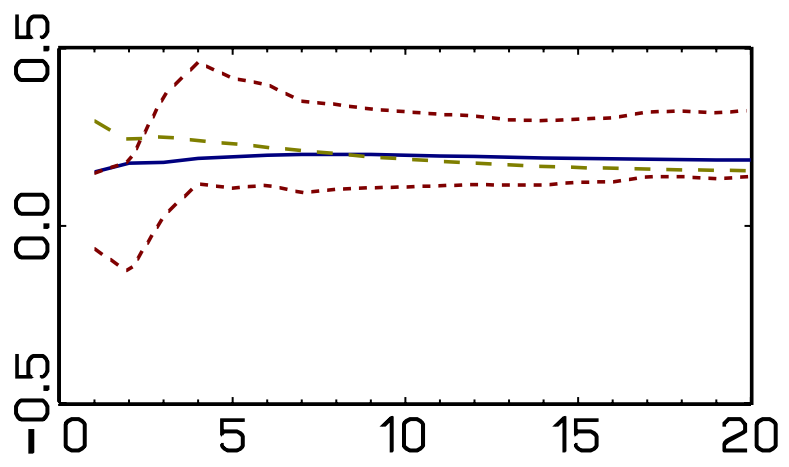

Inflation

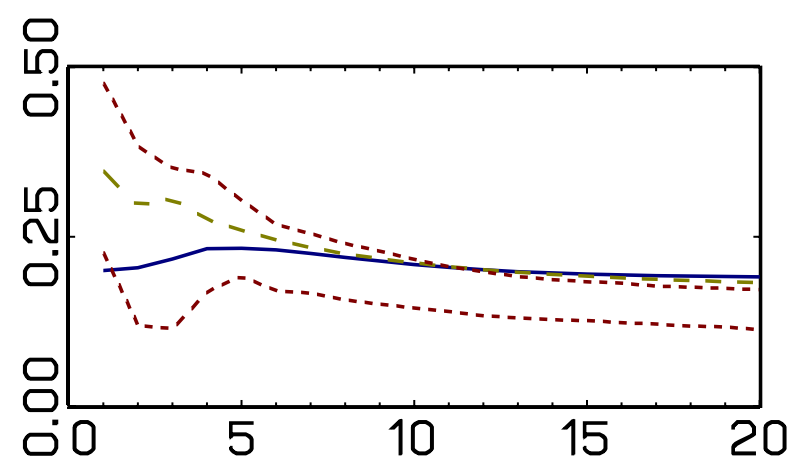

Inverse Velocity

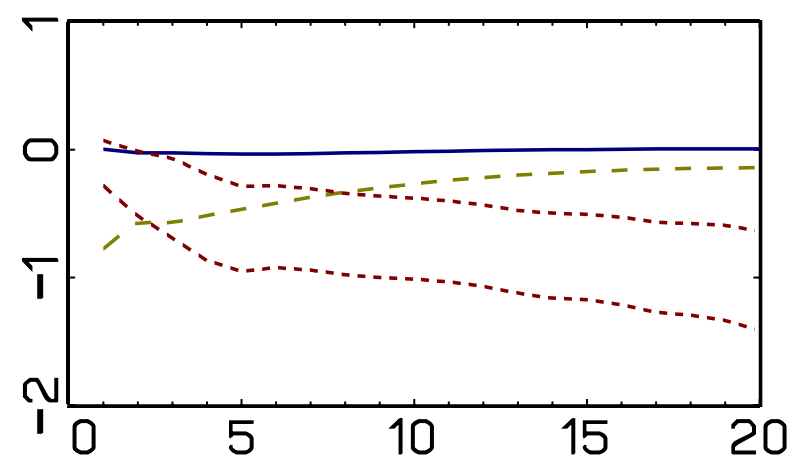

Notes: Figure depicts pointwise posterior 90\% credible interval of impulse responses for VAR (red, dashed) and posterior mean responses for $\operatorname{SBM}(\mathrm{B}): \sigma$ estimated (blue, solid) $\sigma=0.06$ (green, dashed). Responses of inflation and fed funds rate are measured in annualized percentages and responses of real output and inverse velocity are measured in percentage deviations from the steady state. 
Figure 6: Steady State Relationship Between Inverse Velocity and Inflation Target

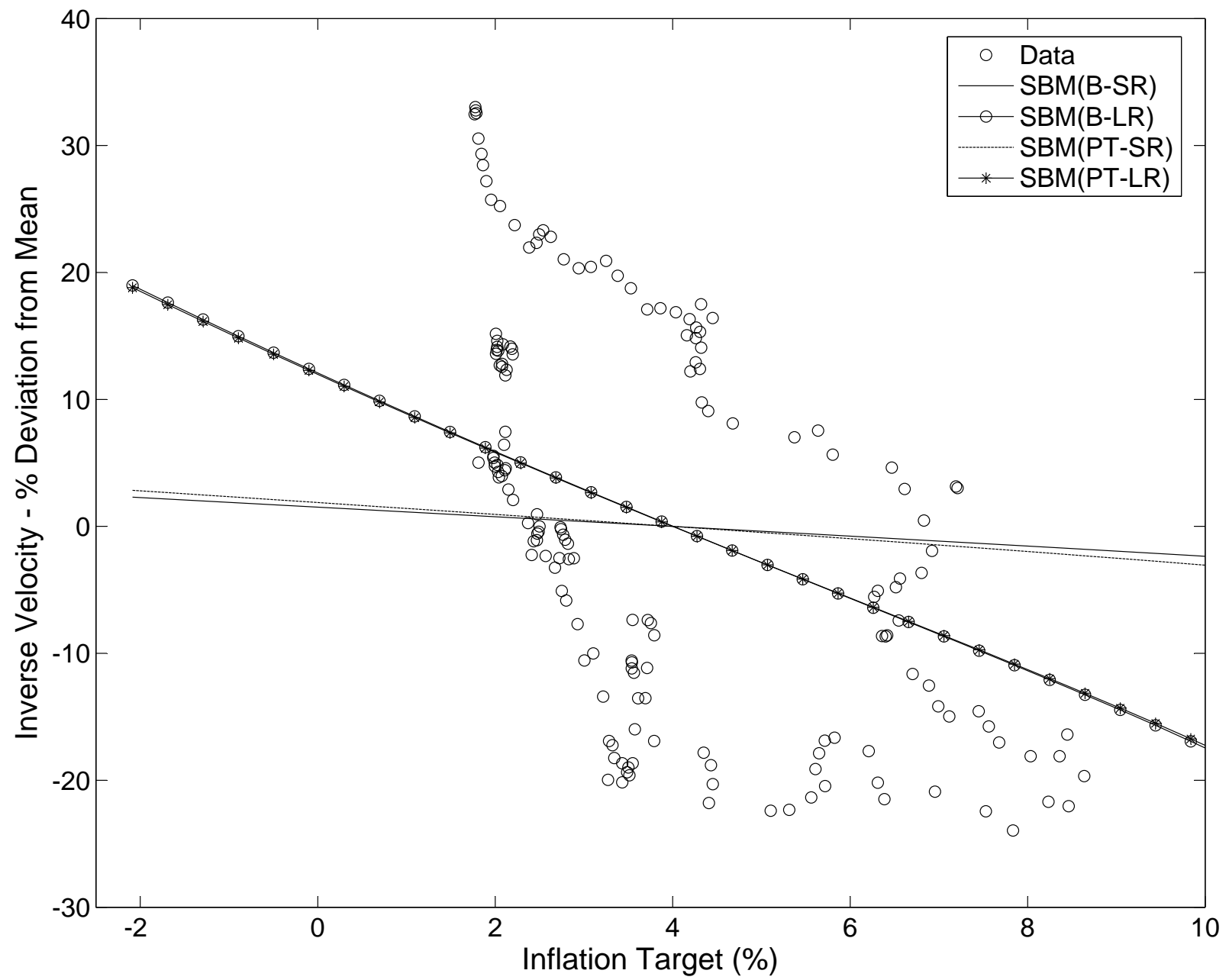

Notes: The dots correspond to inflation and inflation target pairs in our sample and the lines are obtained from different versions of our model. 
Figure 7: Steady State Welfare Costs

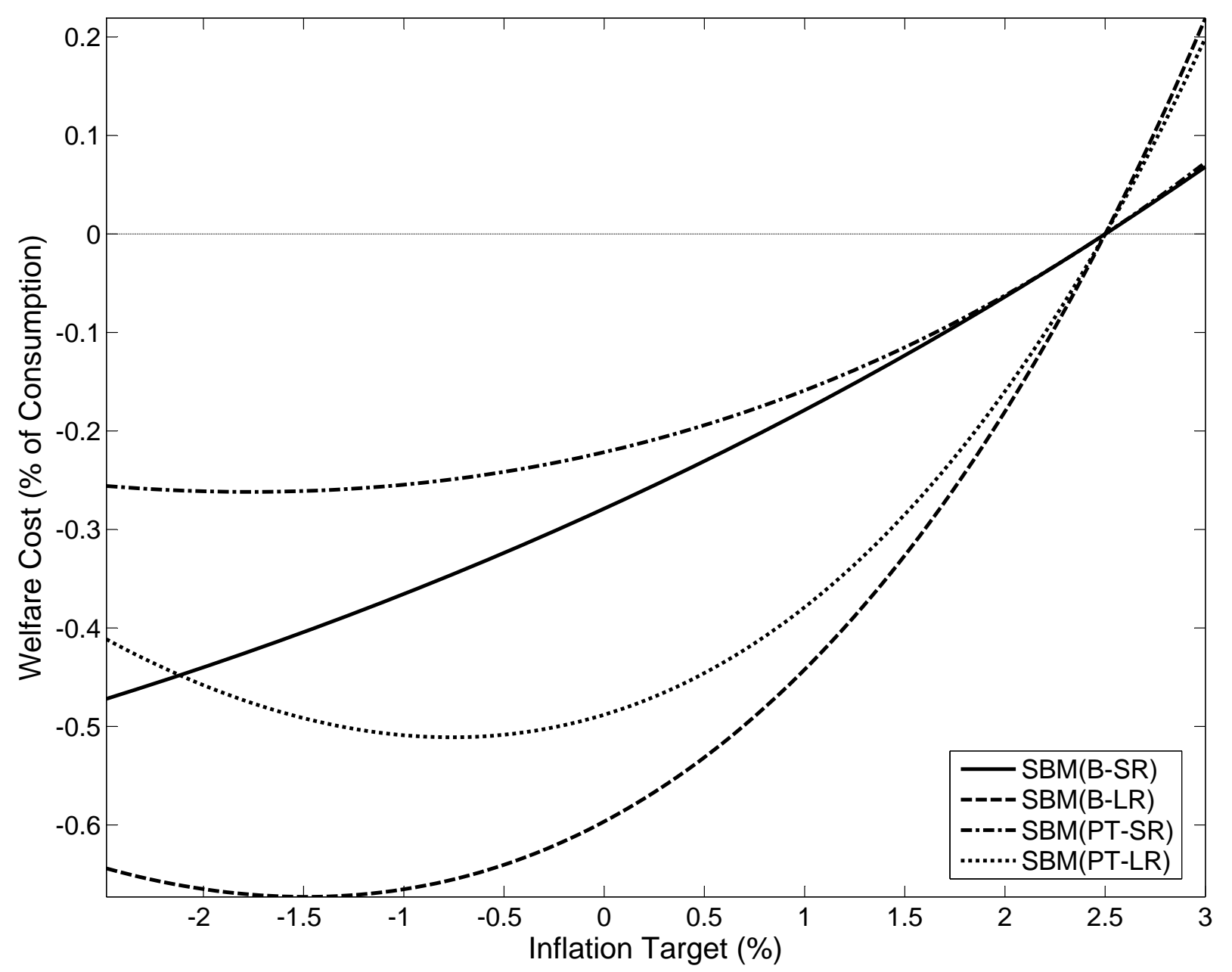

Notes: Welfare costs of deviating from a $2.5 \%$ target in terms of consumption. They are calculated at the posterior mean parameter estimates of the four models. Negative numbers correspond to welfare gains. 
Figure 8: Steady State Welfare with Fixed New Keynesian Channel

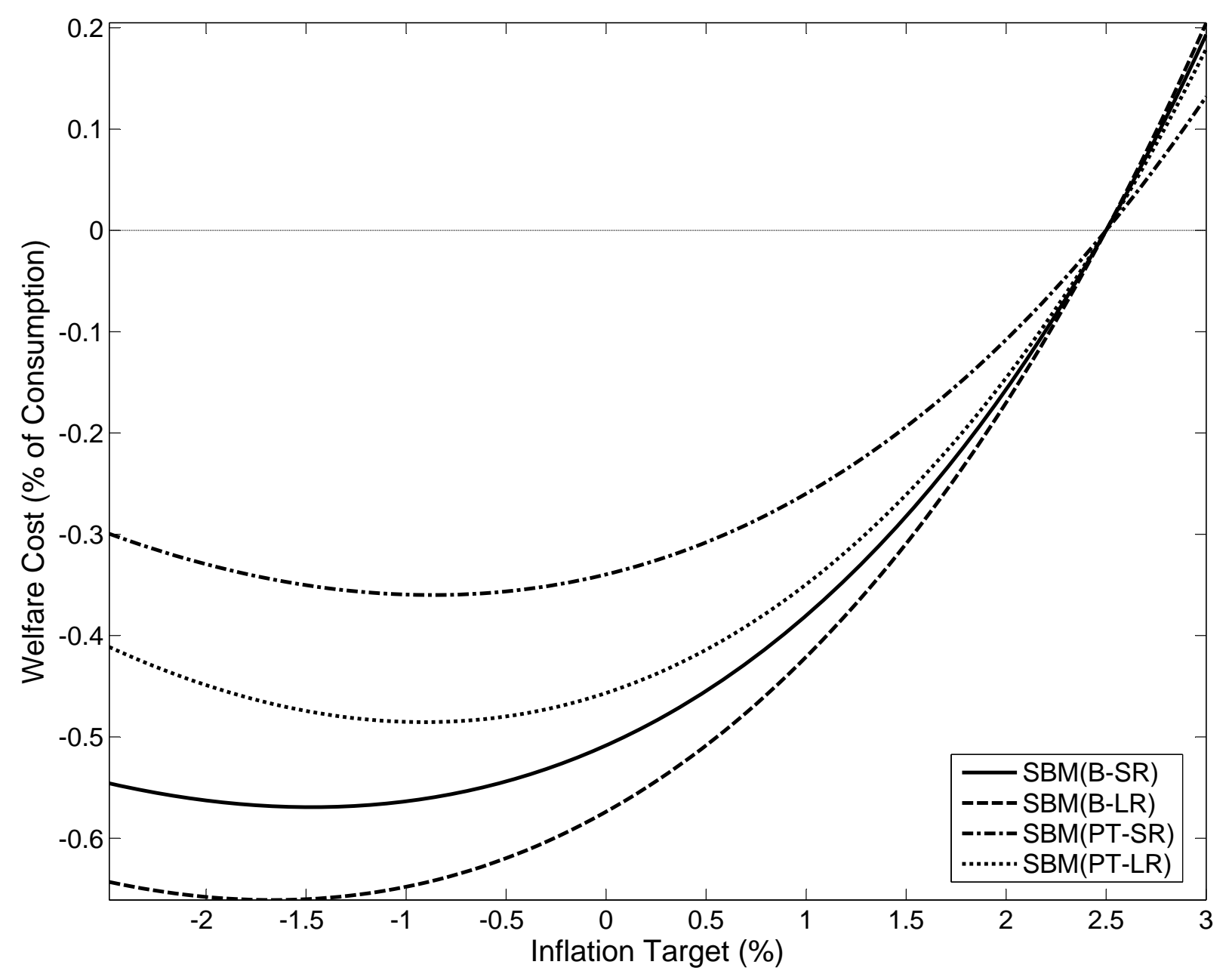

Notes: Figure depicts welfare costs fixing the parameters of the New Keynesian channel at $\zeta=0.81$ and $\iota=0.09$. 
Figure 9: Optimal LONG-RUn Inflation
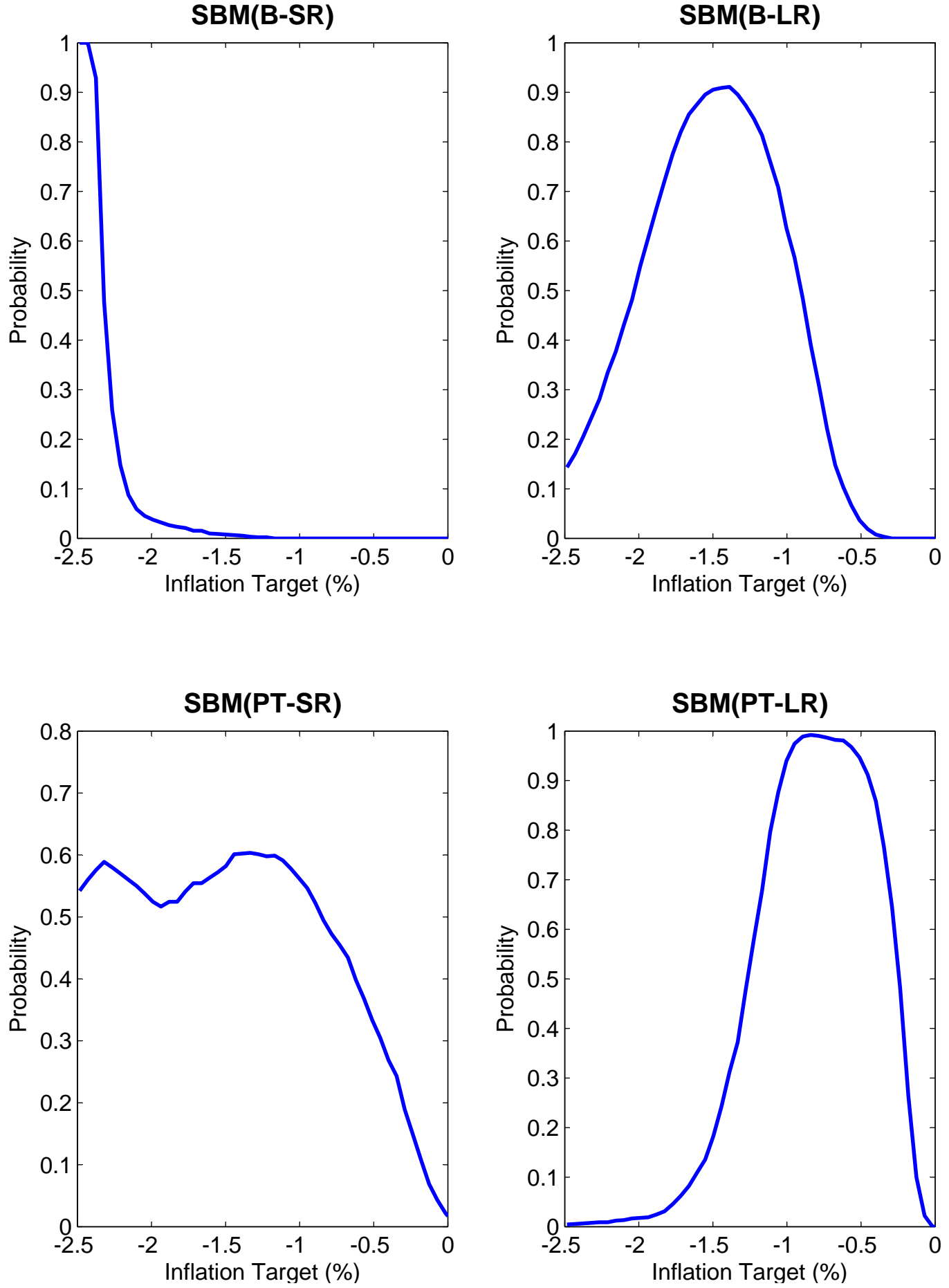

Notes: Figure depicts the posterior probability of the welfare difference between a particular inflation target and the optimal one being less than $0.01 \%$. 